\title{
-Seasonal Variation of the Antarctic Slope Front Occurrence and Position Estimated from an Interpolated Hydrographic Climatology ${ }^{\mathscr{O}}$
}

\author{
Etienne Pauthenet, ${ }^{\mathrm{a}}$ Jean-Baptiste Sallée, ${ }^{\mathrm{a}}$ Sunke Schmidtko, ${ }^{\mathrm{b}}$ and David Nerini ${ }^{\mathrm{c}}$ \\ a Sorbonne Universités, UPMC Univ., Paris 06, UMR 7159, LOCEAN-IPSL, Paris, France \\ ${ }^{\mathrm{b}}$ GEOMAR Helmholtz Centre for Ocean Research Kiel, Kiel, Germany \\ ${ }^{\mathrm{c}}$ Aix-Marseille Université, CNRS/INSU, Université de Toulon, IRD, Mediterranean Institute of Oceanography, \\ UM 110, Marseille, France
}

(Manuscript received 11 August 2020, in final form 8 February 2021)

\begin{abstract}
The Antarctic Slope Front (ASF) is a fundamental feature of the subpolar Southern Ocean that is still poorly observed. In this study we build a statistical climatology of the temperature and salinity fields of the upper $380 \mathrm{~m}$ of the Antarctic margin. We use a comprehensive compilation of observational datasets including the profiles gathered by instrumented marine mammals. The mapping method consists first of a decomposition in vertical modes of the combined temperature and salinity profiles. Then the resulting principal components are optimally interpolated on a regular grid and the monthly climatological profiles are reconstructed, providing a physically plausible representation of the ocean. The ASF is located with a contour method and a gradient method applied on the temperature field, two complementary approaches that provide a complete view of the ASF structure. The front extends from the Amundsen Sea to the eastern Weddell Sea and closely tracks the continental shelf break. It is associated with a sharp temperature gradient that is stronger in winter and weaker in summer. The emergence of the front in the Amundsen and Bellingshausen sectors appears to be seasonally variable (slightly more westward in winter than in summer). Investigation of the density gradients across the shelf break indicates a winter slowdown of the baroclinic component of the Antarctic Slope Current at the near surface, in contrast with the seasonal variability of the temperature gradient.
\end{abstract}

KEYWORDS: Antarctica; Southern Ocean; Fronts; In situ oceanic observations; Interpolation schemes; Principal components analysis

\section{Introduction}

The subpolar Southern Ocean is divided by a quasi-zonal boundary known as the Antarctic Slope Front (ASF), a quasicircumpolar front associated with a westward jet, the Antarctic Slope Current (ASC). The ASF is a sharp hydrographic front along the Antarctic shelf break that separates shelf and open ocean water masses. It facilitates transfers among zonally distant areas and regulates exchanges of water between the Antarctic continental shelves and the open ocean (Thompson et al. 2018). The ASC mean flow and seasonal variability are mainly driven by easterly winds (Sverdrup 1954; Ohshima et al. 1996; Heywood et al. 1998). The mean flow is also partly driven by tides (Flexas et al. 2015; Stewart et al. 2019), and there is evidence that buoyancy forcing is important in the ASF's seasonal cycle (Hattermann 2018). The ASF is known to be strongest in coastal East Antarctica and weakest in West Antarctica' however, its full extent and variability are not well

๑ Denotes content that is immediately available upon publication as open access.

Supplemental information related to this paper is available at the Journals Online website: https://doi.org/10.1175/JPO-D-200186.s1.

Corresponding author: Etienne Pauthenet, etienne.pauthenet@ locean-ipsl.upmc.fr observed and understood (Armitage et al. 2018; Thompson et al. 2018; Vernet et al. 2019).

The meridional exchanges across the shelf break are critical to the on-shelf supply of heat governing Antarctic ice shelf melting (Thoma et al. 2008; Nøst 2011; Thompson et al. 2014). The Antarctic ice sheet has been losing mass at an increasing rate over the past decades (Rignot et al. 2019), and there is currently no consensus on estimates of the future mass balance, due to differences in the representation of physical processes, forcings employed, and initial states of ice sheet models (Seroussi et al. 2020). As a result, the Antarctic ice sheet represents the largest source of uncertainty in projections of future sea level rise (Bamber et al. 2019). The Antarctic ice sheet mass balance is governed by two main processes: mass gain by surface accumulation, and mass loss on its fringe by the iceberg calving and the basal melting of floating ice shelves (Smith et al. 2020). The acceleration of mass loss is due to atmospheric conditions that enhanced basal melting of ice shelves (Pritchard et al. 2012; Smith et al. 2020), and this trend did not clearly emerge from the natural decadal climate variability (Previdi and Polvani 2016; Wouters et al. 2013). For example, in the Amundsen Sea sector, which is perhaps uniquely sensitive to wind-forced oceanic variability, the Antarctic ice sheet retreat is driven by decadal variability (Jenkins et al. 2016, 2018).

The increasing basal melt is sensitive to the delivery of warm Circumpolar Deep Water (CDW) onto the continental shelf, which is tightly linked to atmospheric system variability (Spence et al. 2014; Holland et al. 2019) and to the dynamics of the ASC. The basal melt might also be enhanced by the recent 
shoaling and warming of CDW (Schmidtko et al. 2014; Khazendar et al. 2016) causing more warm water intrusion over the continental shelf (Golledge et al. 2019). Hattermann (2018) tempers this result for the Weddell Sea by revealing a seasonal rise of the ASF thermocline by more than $100 \mathrm{~m}$ during the summer, which could have biased earlier estimates of longterm trends that did not carefully remove the seasonal signal. In East Antarctica, summer warming and shoaling of CDW from a densely repeated temperature section appear unequivocal from 1993 to 2018 and exceed the amplitude of interannual variability over this period (Auger et al. 2021). Such warming and shallowing of CDW could potentially lead increased southward heat transport into cavities beneath the Antarctic ice shelf as a positive feedback to increased ice-shelf melt (Bronselaer et al. 2018; Golledge et al. 2019; Sadai et al. 2020). Another mechanism that could enhance the transport of heat onto the continental shelf is the strengthening of the density gradient in the upper part of the ASF caused by the more buoyant shelf waters due to meltwater release. This would cause a rise of the lower limb thermocline of the ASF and therefore increase the near-bottom transport of CDW transport across the shelf break (Hattermann 2018; Hattermann et al. 2014; Zhou et al. 2014; Daae et al. 2017; Ryan et al. 2020).

The exchanges across the ASF also influence the production and offshore export of Antarctic Bottom Water (AABW; Orsi et al. 1999). AABW plays an important role in sequestering carbon, heat and freshwater in the deep ocean (Purkey and Johnson 2013). Modification of AABW properties and circulation could impact the global ocean's energy budget and sea level (Purkey and Johnson 2010). An increase glacial melt rate is expected to freshen the Antarctic coasts. The more buoyant shelf waters impact the AABW formation (Snow et al. 2016) and drive the observed volume contraction of AABW (Purkey and Johnson 2012). The generation of AABW from dense shelf water could ultimately cease under climate change scenario (Moorman et al. 2020; Lago and England 2019). However, recent observations revealed that dense water supply in the Weddell and Ross Seas are recovering since 2014, complicating our understanding of these mechanisms (Abrahamsen et al. 2019; Silvano et al. 2020).

The ASF is therefore a key frontier between the open ocean and the Antarctic continental shelf that has an outsized role on both the mass balance of the Antarctic ice sheet and the global ocean overturning circulation. Despite this importance for the subpolar Southern Ocean comprehension and climate prediction, there is currently a lack of circumpolar wide observations of the ASF, limiting large-scale understanding of this important feature. In comparison, other large-scale oceanic features, such as the fronts of the Antarctic Circumpolar Current can be studied by high-resolution satellite observations (e.g., Kim and Orsi 2014). Near the Antarctic continental shelf, the winter sea ice and typical cloud cover prevent remote sensing approaches to perform well south of $\sim 60^{\circ} \mathrm{S}$. While recent developments in altimetry are providing promising products of sea surface height (SSH) in sea ice-covered areas (Dotto et al. 2018; Armitage et al. 2018), these approaches remain coarse relatively to the typical width of the ASF and need to be tested against in situ observational counterparts.
The review of Thompson et al. (2018) on the ASC raises the critical need for precise knowledge of ocean properties at the Antarctic margin. The main challenge for creating interpolated ocean products in this region are the sparsity of observations. Circumpolar maps of hydrographic properties at the Antarctic margin have already been produced (Schmidtko et al. 2013, 2014; Pellichero et al. 2017; Thompson et al. 2018; Locarnini et al. 2018; Zweng et al. 2018; Jourdain et al. 2020), and in this study we continue this effort with a specific focus on mapping the ASF.

Interpolating a four-dimensional ocean (3D space and $1 \mathrm{D}$ time) is not trivial since the vertical direction contains structures that evolve at different scales in space and time compared to the horizontal dimensions. Kuusela and Stein (2018) noted that when mapping both temperature and salinity, one should ideally take into account their correlation. In this study we use the covariance matrix of the temperature and salinity $(T-S)$ profiles south of $60^{\circ} \mathrm{S}$ to build a seasonal climatology of the 3D temperature and salinity fields of the ocean's upper layer (10$380 \mathrm{~m}$ ). We chose $60^{\circ} \mathrm{S}$ as the northern limit of the climatology to encompass the water masses on each side of the ASF, allowing to observe any potential spatial variations of the ASF.

We combine a decomposition of the thermohaline structure of the ocean and an optimal interpolation algorithm. This approach ensures that the interpolated results preserve the relationships between temperature and salinity fields, as well as prevent them from producing unphysical vertical structure such as climatological mean density inversion. The decomposition method is a functional principal component analysis (FPCA) of the $T-S$ profiles (Pauthenet et al. 2017), and the horizontal interpolation algorithm includes front-sharpening (i.e., downweighting profiles with regionally atypical characteristics) and bathymetry-respecting components (i.e., different distance weighting in the along slope and across slope direction; Schmidtko et al. 2013). The FPCA requires input profiles of uniform length, constraining us to study the upper portion of the ASF (down to $380 \mathrm{~m}$ ) to avoid discarding a large number of profiles in shallow areas. We use a comprehensive compilation of observational datasets including the observations from instrumented marine mammals (Treasure et al. 2017), providing an improved coverage of the subpolar Southern Ocean. The data and methods are presented in sections 2 and 3 , and the resulting vertical modes and temperature and salinity climatology are given in sections 4 and 5 . The position of the ASF is estimated with a contour method and a gradient method in section 6. We discuss the position and seasonal variability of the ASF in section 7 and list conclusions.

\section{Data}

\section{a. Observations}

The dataset we used is composed of 158026 in situ temperature and practical salinity ${ }^{1}$ profiles located south of $60^{\circ} \mathrm{S}$ from three complementary types of oceanographic platforms: ships,

\footnotetext{
${ }^{1}$ Referred to as temperature and salinity in the following.
} 
a)

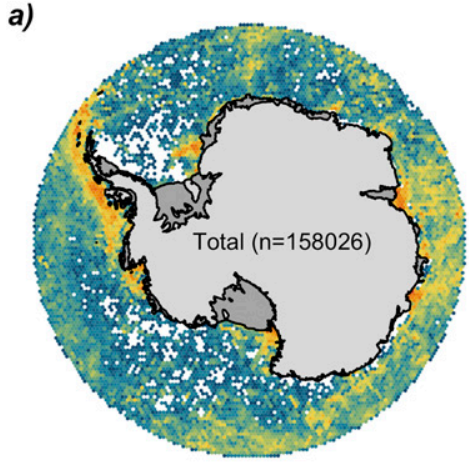

c)

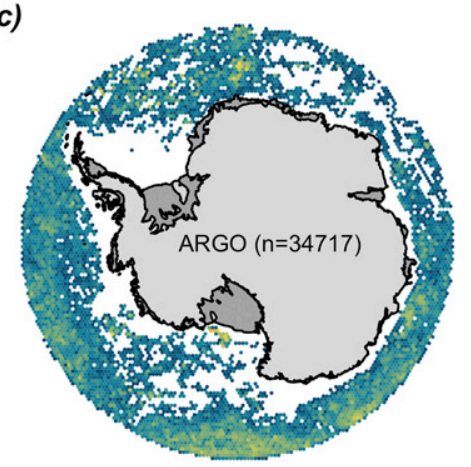

b)

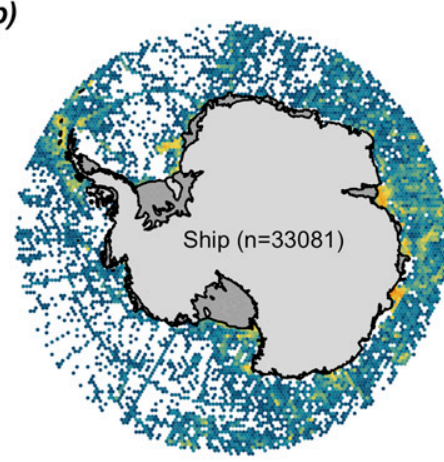

d)

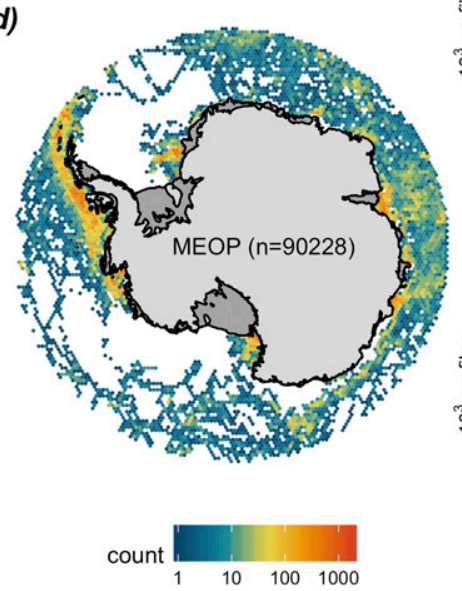

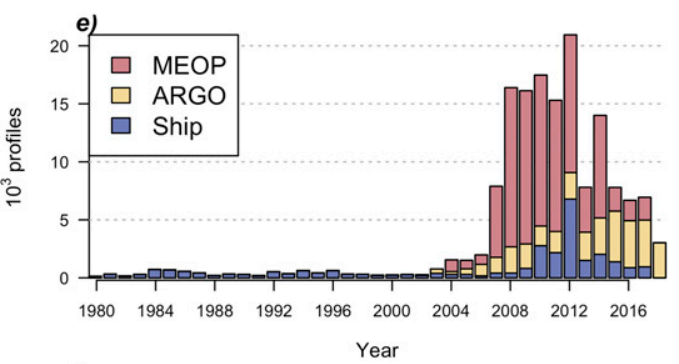
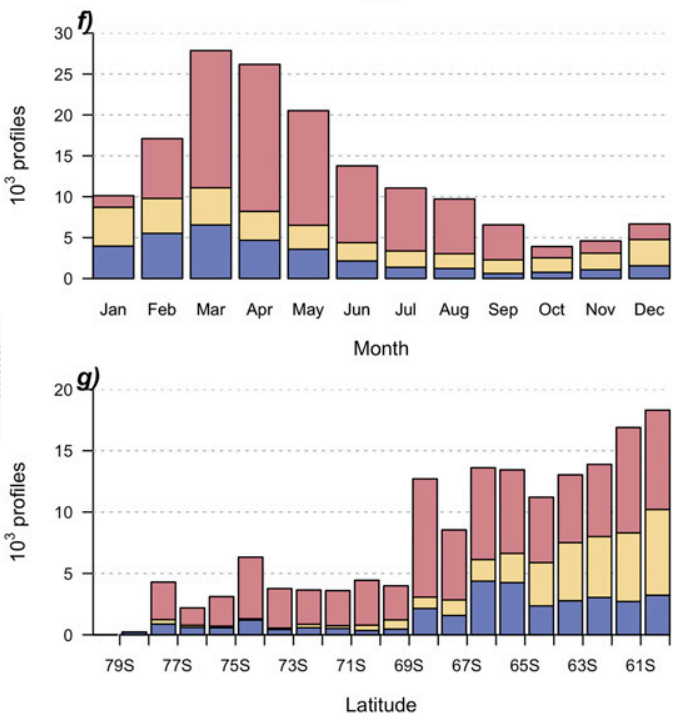

FIG. 1. The distribution (a) of temperature and salinity profiles extending from 10 to $380 \mathrm{~m}$ deep, south of $60^{\circ} \mathrm{S}$, and as sampled from (b) ships, (c) ARGO floats, and (d) marine mammals (MEOP-CTD database). The logarithmic color scale indicates the number of $T-S$ profiles for each hexagonal tile of size $0.5^{\circ} \times 0.5^{\circ}$; white means no data. On the maps in (a)-(d) the ice sheet limit is in dark gray and the terrestrial coast is in light gray. The annual distribution is shown (e) since 1980 only, along with the (f) monthly and (g) latitudinal distributions. The total time series starts in 1910, and $3411 T-S$ profiles were sampled before 1980 , south of $60^{\circ}$.

Argo floats, and marine mammals. The statistical method we use requires every profile to share the same minimum and maximum depth. Any profile whose data do not span these boundaries is discarded. Because the Antarctic continental shelf is typically about $400-500 \mathrm{~m}$ deep (Fig. S1 in the online supplemental material), we choose a depth range of $10-380 \mathrm{~m}$ to keep a maximum number of profiles, especially above the shelf, while maximizing the depth range. The relatively shallow depth range is a compromise that allows us to study the upper part of the ASF only. While the 380-m depth range captures the ASF structure in many regions around Antarctica, there may be limitations for accurately representing the fresh shelf region of eastern Antarctica where the sloping pycnocline that separates the warmer intermediate water from the colder and fresher coastal waters extends sometimes deeper than $380 \mathrm{~m}$ (e.g., Thompson et al. 2018; Heywood et al. 1998; Chavanne et al. 2010).

First, we select the vertical profiles of conductivity-temperaturedepth (CTD) obtained from ship campaigns during the period 1910-2018 (only 1980-2018 are presented in Fig. 1). We use the NOAA World Ocean Database (https://www.nodc.noaa.gov/OC5/ SELECT/dbsearch/dbsearch.html) and augment it from profiles obtained on the PANGEA database (https://www.pangaea.de/).
We only use profiles that have a quality-control flag of 1 plus all of the spatial criteria above, representing a total of 33081 profiles. This ship-based dataset is augmented with float observations from the Argo international program (Argo 2020). The Argo program started in 2000 and has drastically increased the number of ocean observations north of the Antarctic shelf (Fig. 1). All publicly available profiles up to end of 2018 were used in this study, representing a total of 34717 profiles. In addition, we use profiles sampled by equipped seals from the Marine Mammals Exploring the Oceans Pole to Pole program (MEOP, http:// www.meop.net/)(Treasure et al. 2017). This dataset starts in 2004 and considerably increased the number of profiles in the subpolar region and especially over the Antarctic shelf (Fig. 1). We use a calibrated dataset (Roquet et al. 2014) and only use profiles that have a quality-control flag of 1 , representing a total of 90228 profiles.

In this study we compute seasonally varying climatology with a monthly time step, and we note that the observation density is highly biased toward the period $2005-18$, so that the resulting climatology will be mostly representative of this time period. Also, the spatial coverage in winter-spring is very sparse (Figs. 1f,g), especially in the ice-covered area, so particular care needs to be taken when interpreting results in this 
season. Last, we check the quality of all profiles by discarding the ones with PCs that are far out of the main cloud of point in the PC space (see section 3). Similarly, we visually inspected plots of the PC space distribution, where points were color coded with either latitude or longitude, to discard profiles that were in the main cloud of points but far away from other profiles with similar geolocalization. This is an efficient way to quality control the dataset. In the end we are left with 158026 $T-S$ profiles of the 259103 available initially in the region, which represents a loss of $39 \%$ of profiles (Fig. S1). This large number of discarded profiles is mainly due to the large number of MEOP profiles that do not reach $380 \mathrm{~m}$ (90228 MEOP profiles retained of 161407 available south of $60^{\circ}$ S; Fig. 1d).

\section{b. Climatologies}

We compare our climatology with three others. First, we use the Monthly Isopycnal and Mixed-Layer Ocean Climatology (MIMOC, available at https://www.pmel.noaa.gov/mimoc/; Schmidtko et al. 2013). MIMOC is computed from observations ranging from 1970 to 2011 and does not include the instrumented-seal data. It is gridded with a $0.5^{\circ} \times 0.5^{\circ}$ resolution with the same interpolation scheme that is used in this study. The interpolation is a weighted averaging scheme applied along isopycnals, and the influence radius includes front-sharpening and bathymetry-respecting components (see Figs. S5 and S8 in Schmidtko et al. 2014). MIMOC is corrected for the cabbeling biases that are due to the smoothing that artificially mixes water masses, resulting in generally greater densities. The authors adjust the $T$ and $S$ values so that they lie back on the initial isopycnal and conserve density.

Second, we use the recent World Ocean Atlas (WOA18, available at https:/www.nodc.noaa.gov/OC5/woa18/woa18data.html; Locarnini et al. 2018; Zweng et al. 2018). WOA18 is computed from observations ranging from 1955 to 2017 and includes the instrumented-seal temperature data. The interpolation is a weighted averaging scheme described by Barnes (1964). The same interpolation is performed for all of their standard depth levels, on a grid of resolution $0.25^{\circ} \times 0.25^{\circ}$. In addition, the profiles are stabilized with respects to density and are adjusted to not cross the freezing point. We use the $3 \mathrm{D}$ monthly climatology of in situ temperature and practical salinity south of $60^{\circ} \mathrm{S}$ for both climatologies.

Third, we apply our ASF method to the temperature 3D field produced by Jourdain et al. (2020). This climatology is an annual mean with a vertical resolution of $60 \mathrm{~m}$, proposed for the calculation of circum-Antarctic basal melt rates for floating ice, based on climate models, that is suitable for the Ice Sheet Model Intercomparison Project for phase 6 of the Coupled Model Intercomparison Project (ISMIP6).

\section{Method}

\section{a. Optimal interpolation}

In this paper we combine a decomposition in modes of the vertical shape of $T-S$ profiles (Pauthenet et al. 2017) with a spatial interpolation algorithm (Schmidtko et al. 2013). The optimal interpolation algorithm was previously developed and tested to produce climatologies (Schmidtko et al. 2013, 2014, 2017; Pellichero et al. 2017). The thermohaline modes of the ocean were also presented for the Southern Ocean (Pauthenet et al. 2017), the southern Indian Ocean (Pauthenet et al. 2018), and the global ocean (Pauthenet et al. 2019).

The statistical decomposition method is coined functional principal component analysis (FPCA; Ramsay and Silverman 2005 ), and here we apply it to the $\sim 158000 T-S$ profiles to compute the thermohaline modes of the Southern Ocean south of $60^{\circ} \mathrm{S}$. The FPCA is the spectral decomposition of the data's covariance matrix in a function space. It allows us to get a lowdimensional space that exhibits the main modes of variation of the data, in an optimal way according to a variance criterion. The results of the FPCA give two outputs, which are the vertical modes and the principal components (PCs). The PCs are the projection of the data onto the vertical modes. We note that, while the choice of the domain can impact the form of each recovered PC, our climatology is insensitive to choice of the domain because all PCs are used to construct the climatology. The statistical climatology is built by, first, producing monthly mean horizontal maps of the PCs and, second, reconstructing the monthly climatological mean temperature and salinity profiles using the interpolated PCs for each grid point of the spatial interpolation. The vertical modes are also used to identify the main variations that explain the largest amount of variance, hence the typical shape of the $T-S$ profiles and their spatial variation.

The first step of our approach outlined above is to transform the $T-S$ sampled profiles into curves using a decomposition on a B-spline basis. To avoid spurious extrema of the B-splines, the profiles are first linearly interpolated onto a uniform vertical grid every $2 \mathrm{~m}$ (186 levels). At this stage, a classic method to reduce the dimensionality is to apply a standard PCA to the resulting data table of interpolated profiles (e.g., Maze et al. 2017; Jones et al. 2019; Rosso et al. 2020). However, this method does not take into account the fact that the profiles are ordered along depth. The PCA result of the linearly interpolated profiles is invariant with regard to the permutation of either the line or the column of the data matrix. The FPCA includes this dependency with depth and also a first step of dimension reduction prior to the eigenvalue decomposition.

The expected vertical modes depend on 1) the longitude, latitude, and depth extent of the region to study and 2) the number of B-splines, which controls the vertical smoothness. We choose a number of $K=40$ cubic B-splines per profile, which is large enough considering the shallow maximum depth of $380 \mathrm{~m}$ [see the sensitivity test to number of B-splines in Pauthenet et al. (2017)]. Each profile can then be expressed with 40 coefficients that are merged in a table $\mathbf{X}$ of size $N \times L$, with $N$ being the total number of profiles and $L=2 K$ being the number of spline coefficients needed to represent the $T-S$ profiles.

The FPCA is applied on this data table $\mathbf{X}$ and gives two outputs, the eigenfunctions or vertical thermohaline modes and the principal components (PCs). The eigenfunctions are orthonormal modes that define a low-dimensional space that exhibits the main modes of variation of the data, according to a 
variance criterion. The PCs are the projection of the original data onto the eigenfunctions and a profile can be reconstructed by summing the PC values $\left(y_{n, k}\right)^{2}$ weighted by their respective eigenfunctions $\xi_{k}$ :

$$
\left\{\begin{array}{c}
T_{n}=\bar{T}+\sum_{k=1}^{K} y_{n, k} \xi_{k}^{T} \\
S_{n}=\bar{S}+\sum_{k=1}^{K} y_{n, k} \xi_{k}^{S}
\end{array}\right.
$$

where $T_{n}$ and $S_{n}$ are the reconstructed profiles of temperature and salinity; $n=1, \ldots, N$ is the profile index; $k=1, \ldots, K$ are the mode numbers; $p \in\{10,380\} \mathrm{m}$ is the depth; and $\bar{T}$ and $\bar{S}$ are the mean temperature and salinity profiles.

Then we mapped the total $L=80$ resulting PCs on a $0.5^{\circ} \times$ $0.5^{\circ}$ longitude, latitude grid by using an optimal interpolation that is described in detail in Schmidtko et al. (2013). A $0.5^{\circ}$ resolution seems fine enough to map the general location of the strongest lateral gradients that delineate the front and coarse enough to not overfit the profiles in low density regions. However, it is too coarse to capture the finescale processes important to the ASF dynamic (Thompson et al. 2018). We select observations using a spatiotemporal decorrelation scale of $550 \mathrm{~km}$ and 45 days that includes anisotropic distance penalties for moving across bathymetry as well as front-sharpening components that downweight profiles with regionally atypical characteristics. These decorrelation scales are chosen as typical space-time scale of global and we note that some of our results might be sensitive to these choices. However, they have been chosen as typical space-time scale of global large-scale ocean currents as observed by satellite observation (though these observations show large spread; Kuragano and Kamachi 2000), as well as a best compromise between resolution high enough to resolve local scales and meanders and observational coverage available to us. In addition, for a monthly climatology we want some overlap between months to create a smoother seasonal cycle, and prevent arbitrary jumps in data-poor regions, hence the choice of a duration of one month plus a margin of 15 days. The same optimal interpolation is used in Pellichero et al. (2017) to map the mixed layer depth of the Southern Ocean.

Last, the $T-S$ profiles at each grid point and each month are reconstructed by summing the gridded PC values weighted by their respective eigenfunctions, following Eq. (1). Interpolating the principal components instead of the original variables (temperature and salinity) allows us to produce an interpolated product that is entirely consistent between temperature and salinity (the PCs represent a decomposition of both temperature and salinity) and that represents an interpolation of the entire vertical profile consistently (the PCs represent a decomposition of the vertical profiles). We found that our strategy produces a climatology with very limited production of

\footnotetext{
${ }^{2}$ For readability, the $\mathrm{PC}$ values are noted $\mathrm{PC} 1, \mathrm{PC} 2$, etc. in the text and figures and as $y_{1}, y_{2}$, etc. in the equations.
}

unphysical water mass and without density inversion (see Fig. S3 of the online supplemental material and section 5).

\section{b. Horizontal gradients across the shelf break}

In the discussion of this paper, we investigate the gradient of properties across the shelf break, at the position of the ASF. To identify the frontal position around the continent, we investigate cross-slope segments of $\sim 500-\mathrm{km}$ length (typically spanning from the coast to 4000-m depth) and centered over the 1000-m isobath. Along each segment, temperature, salinity, and potential density are extracted from the closest grid points of the climatology, which are then fitted horizontally with a B-spline at 300-m depth. Last, a derivative of each segments is computed (Ramsay et al. 2020), which is equivalent to the gradient of properties across the shelf break. The ASF is defined as the maximum property gradient on the segments.

This analysis was done using $\mathrm{R}$ software, version 4.0.0 ( $\mathrm{R}$ Core Team 2017): the "fda" package for functional data analysis (Ramsay et al. 2020), and the "vwtool" package for the Sobel operator (Sugiyama and Kobayashi 2016).

\section{Vertical modes}

The decomposition of the Antarctic margin thermohaline structure reveals two dominant modes explaining $79 \%$ of the spatiotemporal $T-S$ variance contained in our dataset $(89 \%$ with three modes). This is consistent with earlier work on the thermohaline modes of the ocean that found two to three main modes containing $\sim 90 \%$ of the variance (Pauthenet et al. 2017, 2018, 2019). These vertical modes associated to their spatial distribution (Fig. 2) indicate the main structure of the property fields. In the next section, we project profiles from observations and other climatologies on the modes and compare the cloud of points on the PC1/PC2 map (Fig. 3). Here we provide a short description of these two main modes, which we refer to as thermal mode and haline mode, respectively, because the first mode is primarily associated with variance in the temperature profile and the second mode is primarily associated with variance in the salinity profile.

\section{a. Vertical mode 1: Thermal mode}

The first vertical mode contains $46 \%$ of the variance with a large contribution of the temperature ( $86 \%$, Figs. $2 \mathrm{a}, \mathrm{b})$. It captures a vertical temperature structure associated with the contrast between the warm profiles north of the ASF and the cold ones over the Antarctic shelf (Fig. 2c). This vertical temperature structure is covarying with a slight change of salinity in the upper $250 \mathrm{~m}$ : warmer profiles are fresher and colder profiles are saltier (Fig. 2b). The field of PC1 is highly correlated with the field of temperature around $300 \mathrm{~m}$ (correlation of 0.97; Fig. S2 of the online supplemental material). This correlation implies that temperature at $300 \mathrm{~m}$ is the depth property that represents best the $T-S$ field of the subpolar Southern Ocean between 10 and $380 \mathrm{~m}$. We note that, while capturing most of the $T-S$ variance and thereby being a strong marker of the water-mass variability, this mode is mostly thermally driven, which has small impact on the density relative to salinity. 

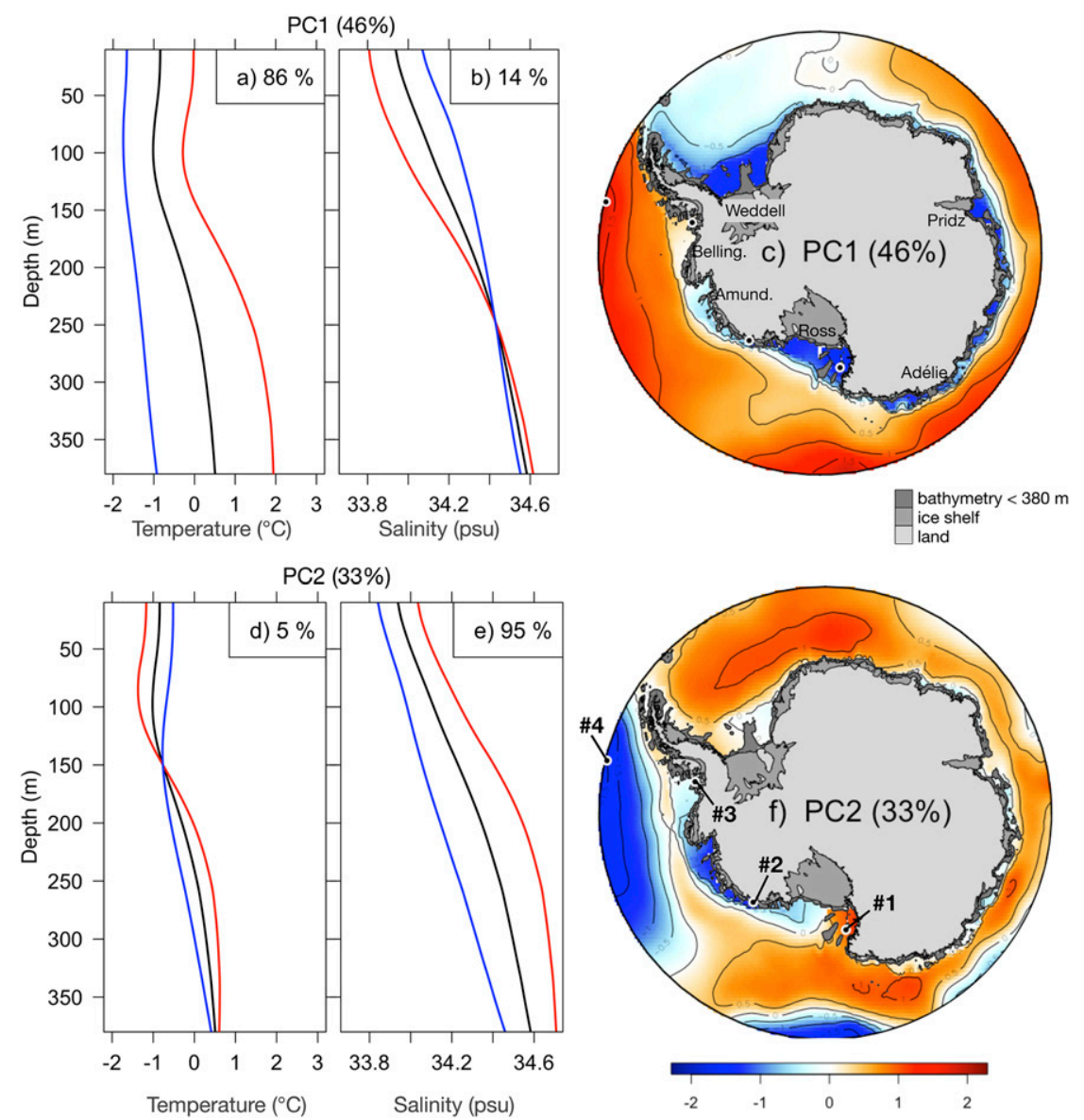

FIG. 2. Optimal interpolation of the principal component (PC) spatial distributions (annual mean) and their associated vertical modes for the (a)-(c) first and (d)-(f) second mode. Colored curves display the effect of each mode $(-1$ in blue and +1 in red) on the mean profile (black). For example, the red profile in (a) and (b) is the $T-S$ profile reconstructed with PC1 $=1$ alone. The percentages in Antarctica in (c) and (f) are the amounts of variance explained by the PC displayed, and the percentages in the legends of (a), (b), (d), and (e) are the variance contained by each variable ( $T$ or $S$ ) on the displayed mode. The locations of the Weddell Sea, Prydz Bay, Adélie Coast, Ross Sea, Amundsen Sea, and Bellingshausen Sea are indicated in (c). The locations of four typical profiles are indicated in (c) and (f) with black and white dots, corresponding to the four example profiles displayed in Fig. 3, below.

\section{b. Vertical mode 2: Haline mode}

The second vertical mode contains $33 \%$ of the variance with a major contribution of the salinity ( $95 \%$, Figs. 2 d,e). It captures variations of salinity throughout the whole water column, slightly amplified around $250 \mathrm{~m}$ (Fig. 2e). The large positive values of PC2 in the open ocean are highlighting regions where CDW (slightly saltier than their surrounding) upwell south of the Southern Antarctic Circumpolar Current Front (SACCF) with maxima on the Ross and Weddell Gyres. The high PC2 values on the continental shelf seem associated with known regions of the densest High Salinity Shelf Water formation (Weddell and Ross Sea, Prydz Bay, and the Adélie Coast), the high salinity of which is largely due to local brine release from sea ice formation. The spatial distribution of $\mathrm{PC} 2$ is best correlated with salinity around $200 \mathrm{~m}$ (correlation of 0.96 ; Fig. S2 of the online supplemental material).

\section{c. $P C 1 / P C 2$ map}

The FPCA framework provides an opportunity to compare profiles' shapes in a single plot. Indeed, the PC1/PC2 map contains $79 \%$ of the variance (Fig. 3). On this map, each point is a temperature and salinity profile. The distribution of the profiles displays a continuous shape, sorting the stations from dense $[-1.5,1.2]$ to light $[2,-1.5]$ waters at $380 \mathrm{~m}$ (Fig. 3c). The left side of the PC1/PC2 map contains the cold waters with salty or fresh profiles (example profiles labeled \#1 and \#2; Figs. 3d,e). In contrast, the right side of the PC1/PC2 map contains the warmer waters north of the ASF, either over the continental shelf along the Western Peninsula (profile label \#3) 
a) Temperature $\left({ }^{\circ} \mathrm{C}\right)$ at $380 \mathrm{~m}$
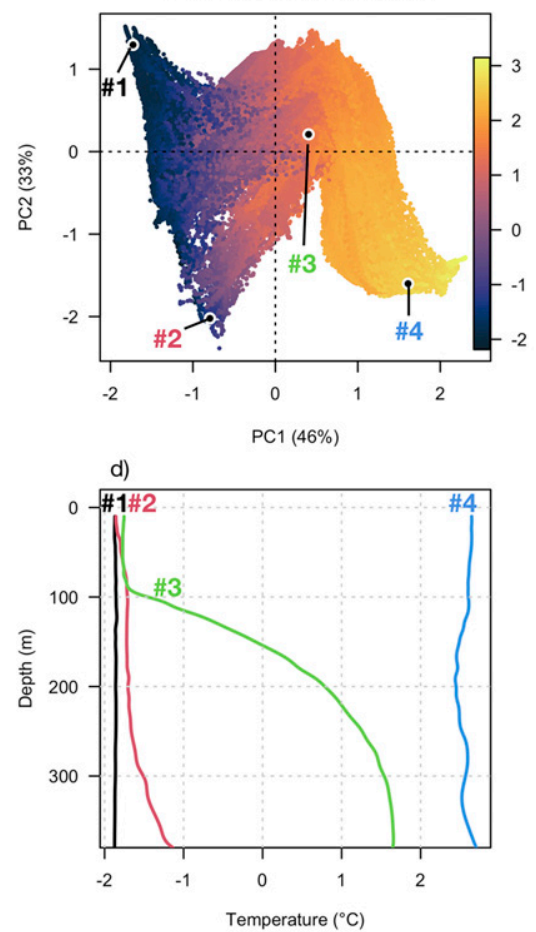

b) Salinity (psu) at $380 \mathrm{~m}$
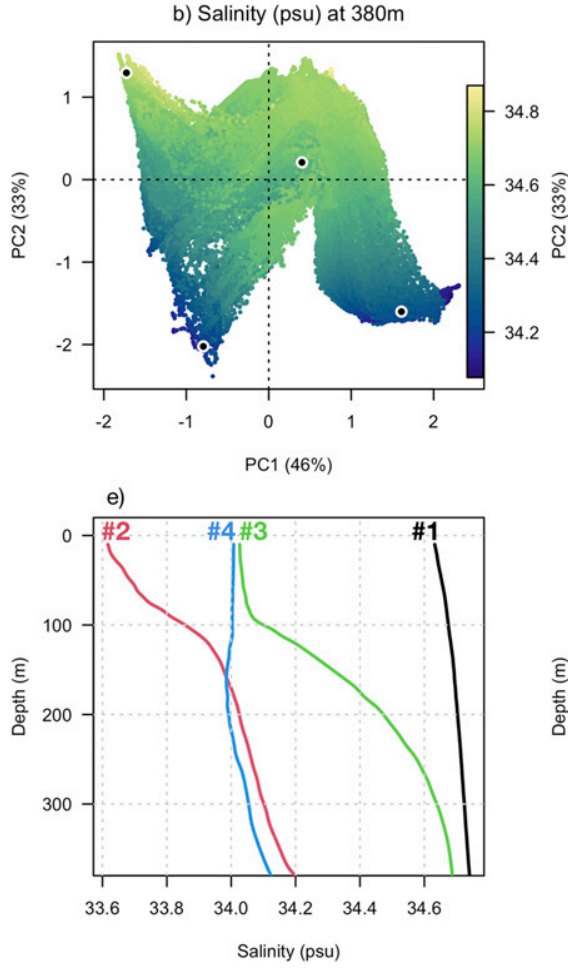

c) Potential Density $\left(\mathrm{kg} \cdot \mathrm{m}^{-3}\right)$ at $380 \mathrm{~m}$
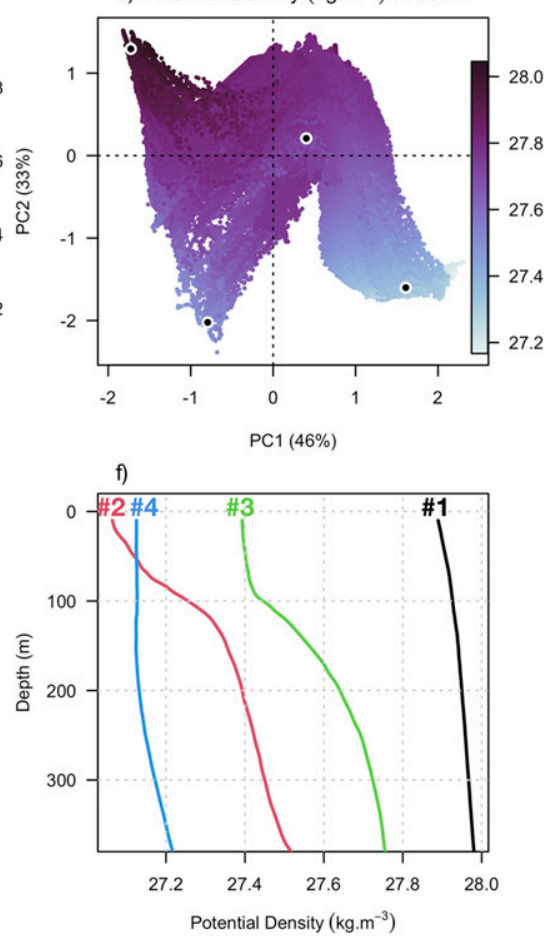

FIG. 3. Temperature and salinity profiles, sorted according to their shape on the PC1/PC2 map. The color bars display (a) temperature, (b) salinity, and (c) potential density at $380 \mathrm{~m}$, i.e., the bottom boundary of the climatology. (d)-(f) Four profiles plotted against depth to represent typical profiles from a dense shelf (1), fresh shelf (2), warm shelf (3), and a profile located in the open ocean in the Pacific (4).

or north of the shelf break (profile label \#4). Thompson et al. (2018) defined three types of Antarctic shelf: the dense, fresh, or warm shelf. Profile 1 is located in the western Ross Sea and corresponds to a dense shelf. Profile 2 is in the eastern Ross Sea on a fresh shelf, and profile 3 is in the Bellingshausen Sea and is a typical warm shelf (Figs. 3d-f). This diagnostic is an efficient tool for evaluating the profiles contained in a dataset. Similarly, Sun et al. (2020) compare different hydrographic products by clustering previously defined water column metrics such as the vertical temperature minimum or the salinity at the vertical temperature maximum. They find that comparing the resulting classes from different hydrographic products can highlight the relative differences between regimes and is a promising tool for the evaluation of large model ensemble.

\section{Statistical climatology of the Antarctic margin}

We interpolate optimally the $80 \mathrm{PCs}$ for each month and reconstruct the profiles on the $0.5^{\circ}$ grid. We obtain a statistical climatology of the ocean south of $60^{\circ} \mathrm{S}$ between 10 and $380 \mathrm{~m}$. In this section we investigate the produced climatology to assess its quality. The temperature ranges from $-2.62^{\circ}$ to $5.20^{\circ} \mathrm{C}$, and the salinity ranges from 33.14 to 34.87 psu. While some linear combinations of PCs could produce vertical density inversions, such inversions are not produced by the optimal interpolation. We note, however, that small patches of erroneous profiles are produced in the open ocean along the Western
Peninsula in October $\left(80^{\circ}-70^{\circ} \mathrm{W}\right.$; Fig. S3 of the online supplemental material). We do not correct these profiles because they do not impact the mapping of the ASF.

The spatial distribution of PC1 is best correlated with temperature at $\sim 300 \mathrm{~m}$ (correlation of 0.97 ), and PC2 is best correlated with salinity at $\sim 200 \mathrm{~m}$ (correlation of 0.96 ) (see section 4 and Fig. S2 of the online supplemental material). Therefore, these depths are most representative of the horizontal changes in the vertical structure of the profiles. They are shown in Fig. 4. The ASF is apparent circumpolarly on the temperature and salinity maps (Fig. 4), separating the warm and salty waters in the north from the cold and fresh waters over the continental shelf. There are exceptions to that schematic in regions of dense water formation where salinity is high over the continental shelf, e.g., in the western part of the Ross and Weddell Sea and at Prydz Bay. The dense water formation along the Adélie Coast (Williams et al. 2008) is not apparent here.

The Weddell and Ross Gyres are delineated by high salinity values (Fig. 4). The CDWs in the Weddell Gyre are cooler than on the rest of the Antarctic perimeter. In the southeastern part of the Weddell Sea, the very cold water of the continental shelf appears to extend northward, north of the slope and toward the Weddell Gyre, which could indicate a wide seasonal variability in the ASF, but we actually found this to be poorly constrained by observations because of a lack of data in this region in spring and winter (Fig. S4 of the online supplemental material). 

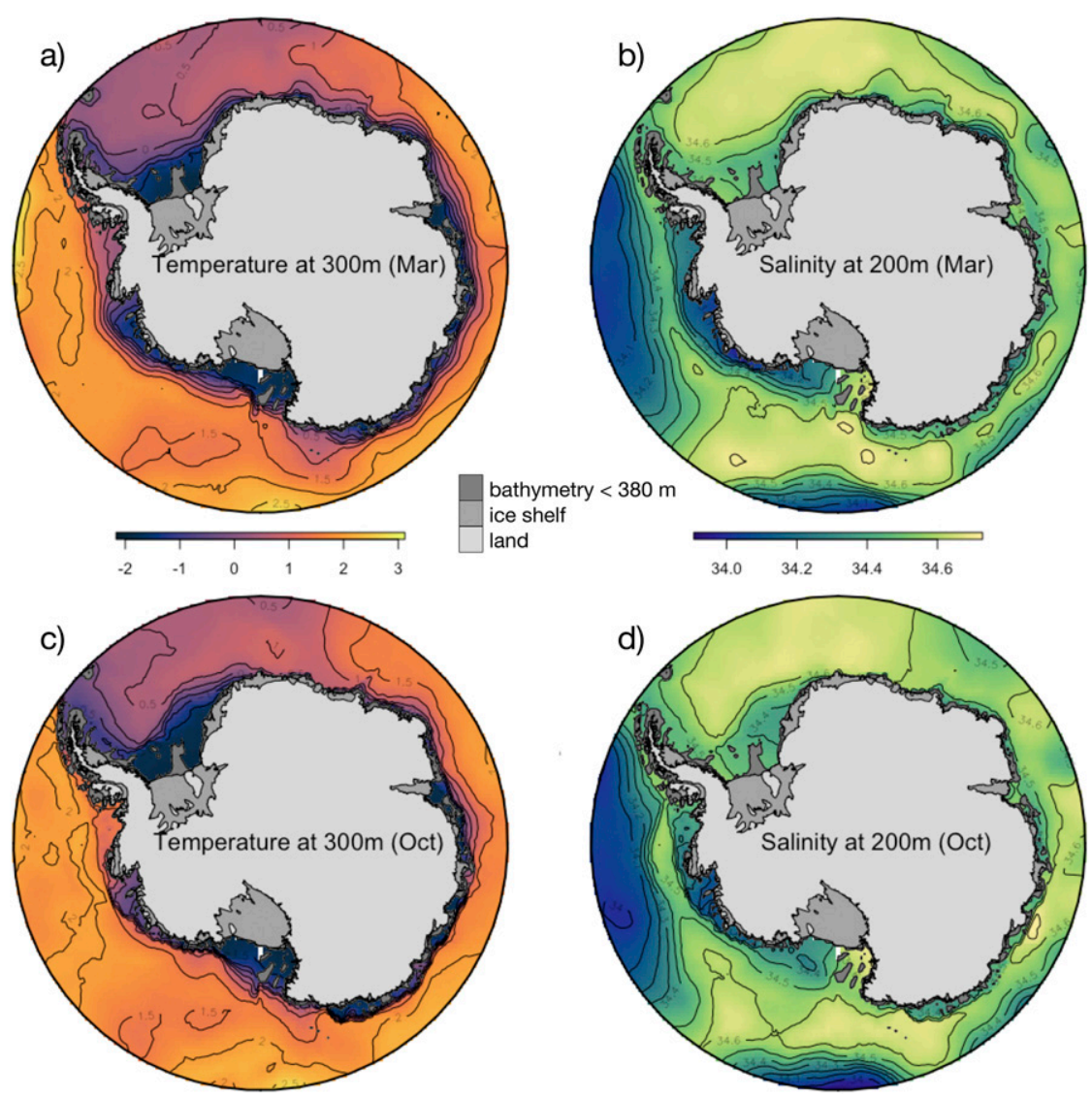

FIG. 4. (left) Temperature $\left({ }^{\circ} \mathrm{C}\right)$ at $300 \mathrm{~m}$ and (right) salinity (psu) at $200 \mathrm{~m}$ are best correlated with PC1 and PC2 maps, respectively, here for the months of (a),(b) March and (c),(d) October.

The climatology appears reasonably well constrained by the vertical modes within the limits of the sparse and seasonally biased data coverage.

\section{Comparison with WOA18 and MIMOC}

To validate the property distribution of our climatology we compare the density distribution (Hyndman 1996) of profiles in the PC1/PC2 map of our climatology (Fig. 5b) with the density distribution of profiles of two other climatologies: MIMOC (Fig. 5d) and WOA18 (Fig. 5c). To obtain the PCs of both WOA18 and MIMOC climatologies, we interpolate each profile to a 2-m-depth resolution, fit B-splines on the interpolated profiles, and project the coefficients of decomposition in B-splines onto the eigenfunctions originally computed on the observed profiles [see Eq. (2) in Pauthenet et al. 2019]. We also produce, for comparison, the density distribution of the PCs for the observed profiles that were used to compute the climatology (Fig. 5a). Note that the spatiotemporal sampling of the observed profiles is heterogeneous compared to the regular gridded products, therefore the density distribution in the PC1/PC2 map is biased by the sampling. Yet the space occupied on the PC1/PC2 map is an indicator of the profiles represented in each product in comparison with the observations.
The density distribution of the observations, that is, before climatological interpolation, presents a dipole with probability maxima for the typical profile south $[-1.3,0]$ and north $[0.6$, 0.6] of the ASF (Fig. 5). A third probability maximum is present around $[1,1.5]$ and contains the Pacific Ocean profiles that are north of the Polar Front (see PC spatial distribution on Fig. 2). Around these three poles, the observations also show a wide coverage of the PC1/PC2 map, associated with low density, arguably representing outliers in the temperature/salinity profiles that are present in the dataset (Fig. 5a). In comparison, the climatology we produced agrees well with the contours of high density distribution of the observations (blue contours on Fig. 5b) and does not present the extreme values of the observations, because individual low probability extremes are discarded by the interpolation procedure. An unwanted consequence is that our mapping may discard infrequently sampled water masses that exist persistently. For instance, the very fresh surface waters $(S<33.1 \mathrm{psu})$ caused by the seasonal ice melting are not reproduced in our climatology (Fig. S3 of the online supplemental material).

The WOA18 climatology distribution on PC1/PC2 (Fig. 5c) is also centered on the observations and presents a wider coverage of the PC1/PC2 map with low probability profiles, compared to our climatology. This means that WOA18 better 
a) Observations
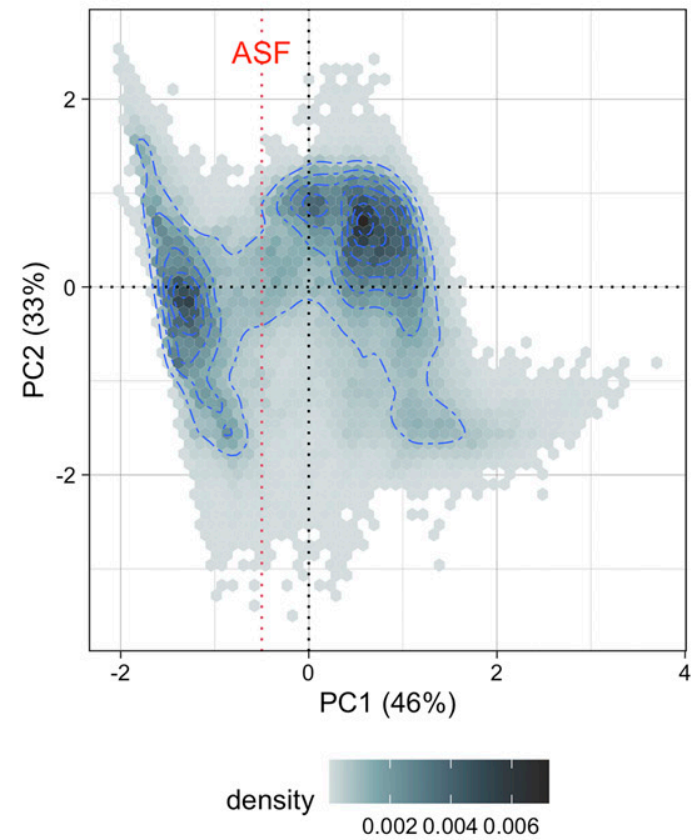

c) WOA18
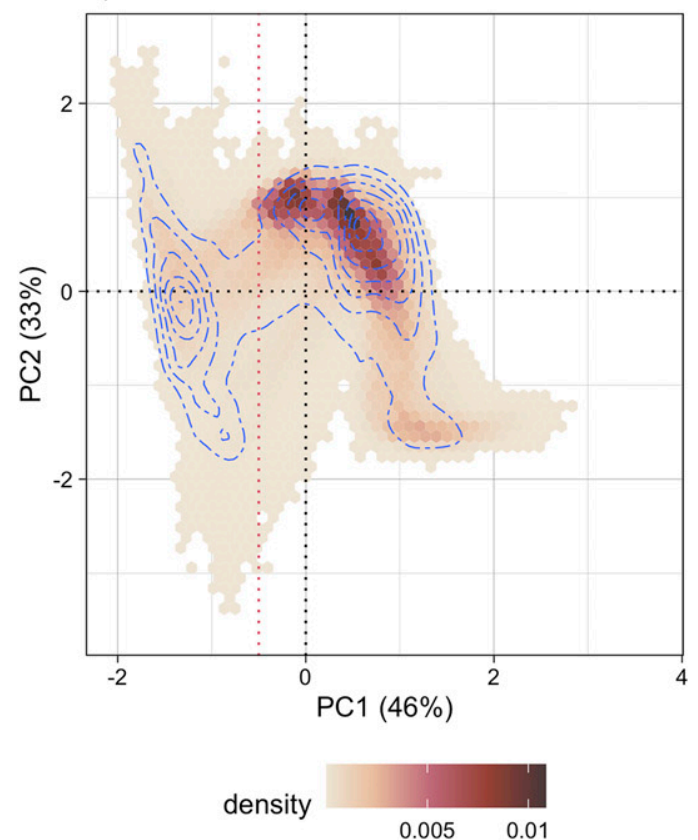

\section{b) Climatology}
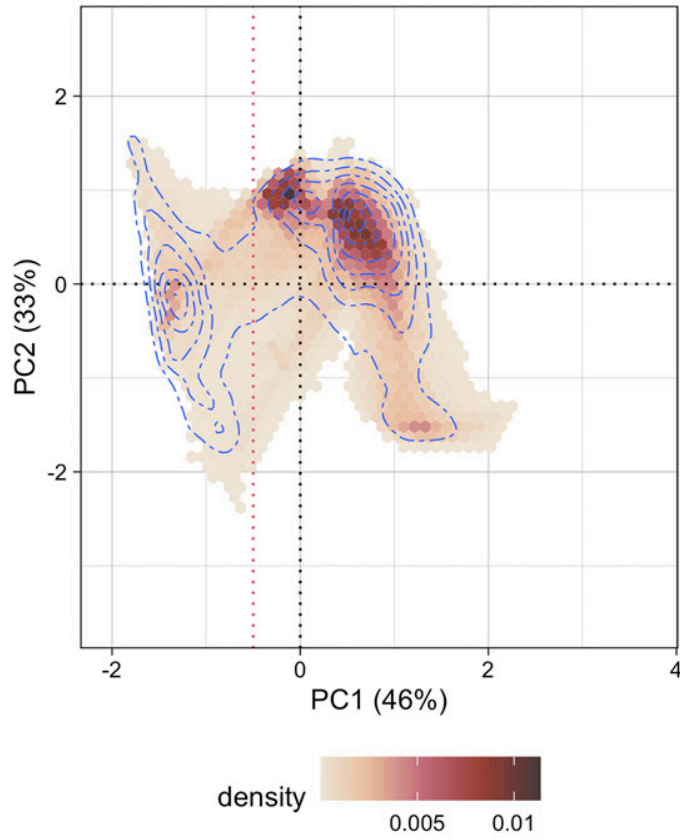

d) MIMOC

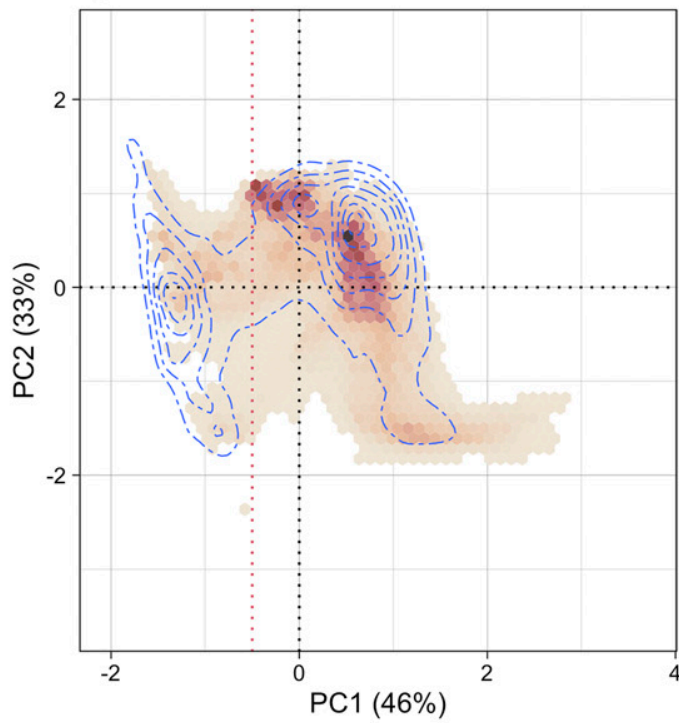

density

FIG. 5. Comparison of the density distribution of observations and climatologies on the 2D map of the PCA, showing the projection of (a) the observed $T-S$ profiles and (b) the monthly climatological profiles computed in this study. The PCs of the (d) monthly WOA18) and (d) MIMOC) are also shown. The PCs of (b), (c), and (d) are computed by projecting the profiles on the modes computed with the observations. The blue-dashed contours on the four panels are density contours of the observations in (a) to be compared with the distribution of the three climatologies. The vertical red dotted line is $\mathrm{PC} 1=-0.5$, corresponding to a contour that matches approximately the ASF (see the spatial distribution of PC1 in Fig. 2c). 

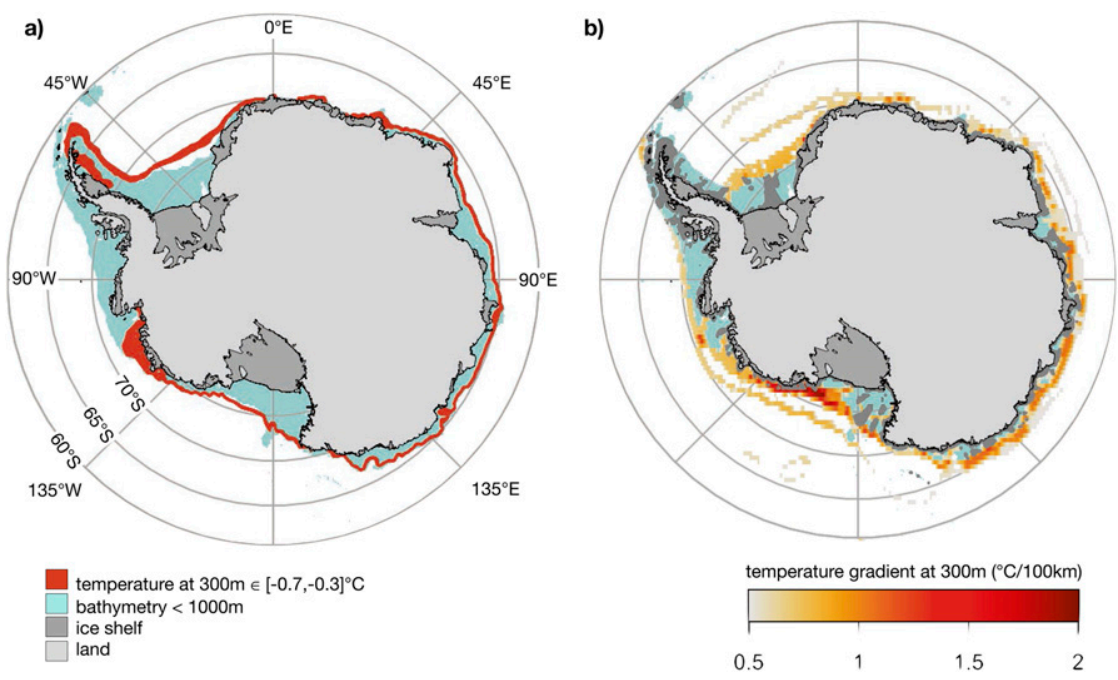

FIG. 6. The mean ASF represented with (a) the temperature at $300 \mathrm{~m}$ that ranges from $-0.7^{\circ}$ to $-0.3^{\circ} \mathrm{C}$ (red) and (b) the gradient of temperature at $300 \mathrm{~m}\left[{ }^{\circ} \mathrm{C}(100 \mathrm{~km})^{-1}\right]$, truncated at $0.5^{\circ} \mathrm{C}(100 \mathrm{~km})^{-1}$. The bathymetry shallower than $1000 \mathrm{~m}$ is in blue.

captures the extrema of the observed profiles that are located farther away from the three main poles in the histogram. The right side of the density distribution, that is, north of the ASF (Fig. 5c), is less fuzzy, supporting our assertion that the smoothing method of WOA18 might overfit the sparse data in the high latitudes but is working adequately in areas with sufficient sampling. Jourdain et al. (2020) noted that the temperature fields of WOA18 do not seem able to account for the strong horizontal gradients over the very narrow continental shelf of East Antarctica (see Fig. S1 in Jourdain et al. 2020). A qualitative comparison of the observed temperature at $250 \mathrm{~m}$ with the gridded products shows that WOA18 and our climatology reproduce similarly the temperatures near the shelf slope (Fig. S5 of the online supplemental material).

In the MIMOC climatology, the fields are smoothed similarly to our climatology (Fig. 5d). This is expected as MIMOC is built with the same optimal interpolation algorithm as our study but is applied on isopycnals. Some parts of the left density maximum are missing when compared with the observations. These correspond to waters over the continental shelf that are absent in MIMOC because of the lack of data in East Antarctica, because MIMOC does not include the marinemammals dataset. The misrepresentation of the cold shelf temperature stands out on a map of temperature difference between observed and gridded data at $250 \mathrm{~m}$ (Fig. S5 of the online supplemental material).

In conclusion of this section 5a, our climatology reproduces well the frequent water masses of the observations and does not create additional water masses that are not observed. Like MIMOC, it discards the low-probability extremes, which is also a potential caveat because it may remove infrequently sampled water masses that exist persistently. Most important, the data over the continental shelf are reproduced (left extremity of the density distribution in Fig. 5). These profiles are also reproduced by WOA18 but are absent in MIMOC because of the lack of data in East Antarctica. We applied the two ASF proxies presented in the next section on WOA18, MIMOC, and the climatology from Jourdain et al. (2020) for comparison of the quality of the mean field (see the online supplemental material).

\section{Antarctic Slope Front position}

Finding the position of a front is not trivial (Chapman et al. 2020). Manifestations of the slope front in the surface temperature field are subtle, and it is actually best marked as a meridional temperature gradient below the surface layer (Jacobs 1991). In the following we seek fingerprints of the ASF in the temperature field at $300 \mathrm{~m}$, because this depth level was associated with the largest temperature signal in PC1 (Fig. 2a) and so is arguably displaying the most marked temperature change across the ASF. We present two different ways to identify the Antarctic Slope Front (two ASF proxies): a property contour method (Fig. 6a) and a gradient method (Fig. 6b), which both have drawbacks and advantages that are discussed in turn.

\section{a. Property contour method}

Pauthenet et al. (2017) proposed to map oceanic fronts using contours of the main PCs, because they represent the main changes in stratification and follow closely the classical front definitions in the ACC. In the present paper, PC1 captures the contrast between profiles north and south of the ASF in the first $380 \mathrm{~m}$ (Figs. $2 \mathrm{a}-\mathrm{c}$ ). The contour of $\mathrm{PC} 1=-0.5$ seems to match well the shelf break except in the Weddell Sea where it is located farther north (Fig. 2c). In addition, in a PC1/PC2 map, which conveniently summarizes the main underlying $3 \mathrm{D}$ watermass structure of the ocean, it appears clear that a contour of PC1 $\sim-0.5$ is associated with a front separating the two dominant modes of water mass types (Fig. 5). The PC contour 
selection is convenient because it simplifies the front into a single continuous line; however, it removes a part of the variability not captured by the mode used. To alleviate this issue, we decided to use a contour of properties instead of a contour of PC. Temperature at $300 \mathrm{~m}$ is best correlated with the first vertical mode spatial distribution (correlation of 0.97 ; Fig. S2 of the online supplemental material). So, we select temperature values that follow the Antarctic slope, from $-0.7^{\circ}$ to $-0.3^{\circ} \mathrm{C}$ at $300 \mathrm{~m}$ (Fig. 6). This range of temperature corresponds roughly to the temperature at $300 \mathrm{~m}$ of the profiles located along the $\mathrm{PC} 1=-0.5$ contour $\left(-0.4^{\circ} \mathrm{C} \pm\right.$ a standard deviation of $\left.0.3^{\circ} \mathrm{C}\right)$.

Choosing a range instead of a single value of temperature highlights regions where gradients of temperature are sharper (all contours collated in a single line), or weaker (contours spread over a wider area). While in the East Antarctic and Ross Sea sectors $\left(\sim 0^{\circ}-135^{\circ} \mathrm{W}\right)$ the ASF appears sharp and tightly following the shelf break (Fig. 6), it is in contrast much looser in the Amundsen Sea $\left(\sim 135^{\circ}-100^{\circ} \mathrm{W}\right)$ and Weddell Sea $\left(\sim 60^{\circ} \mathrm{W}-0^{\circ}\right)$ sectors and does not show up at all in the Bellingshausen Sea sector $\left(\sim 100^{\circ}-60^{\circ} \mathrm{W}\right)$.

The less-sharp interface in the Weddell Sea sector is likely an artifact of both the seasonal sampling bias and the shallow depth range as the sloping ASF pycnocline extends deeper than $380 \mathrm{~m}$ in this region (e.g., Heywood et al. 1998; Chavanne et al. 2010; Thompson et al. 2018). In this way, the sharpness of the front may be an indicator of changes in the vertical structure of the front, rather than its horizontal extent. This annual mean picture is associated with little seasonal variability: the full range of temperature contours is present from the Amundsen to the Weddell Sea all year long, except locally in some places along the coast of the Enderby Basin $\left(0^{\circ}-45^{\circ} \mathrm{E}\right)$ in winter and spring. Overall, the main circumpolar-wide seasonal pattern depicts a slope front that appears thinner (sharper gradient) in winter and wider (looser gradient) in summer (Fig. 7). We quantify this distance between the contours perpendicular to the 1000-m isobath and find that the front is wider and has the largest seasonal variation in the Weddell sector (Fig. 8). The ASF width shows a more pronounced seasonality in the Amundsen and Ross sectors than in East Antarctica (Fig. 8). Note that the ASF width quantified here $(\sim 10-100 \mathrm{~km})$ is of the same order of magnitude as the spacing between points on the climatology grid $(\sim 50 \mathrm{~km})$. Hence, the resulting ASF widths are a best estimate dependent on the interpolation scheme along the segments.

The location of the regional transition between no contour in the Bellingshausen Sea to presence of contours in the Ross Sea sector is seasonally variable. The transition is East of the Amundsen Sea in summer (November-March), and closer to the Ross Sea in winter (May-October). The Weddell Sea is another region where the range of contours appears markedly seasonally variable, with large northward excursion of the contours away from the shelf break in spring (September-November). However, we note that in the Weddell Sea in general, and in particular in spring, wide regions are associated with no observations within a $200-\mathrm{km}$ radius (as indicated by the purple hatching in Fig. 7), so we have very little confidence in results in the Weddell Sea, and believe that the loose gradients and seasonal excursion are artifacts of unconstrained interpolation.
The choice of defining a proxy of the ASF position as a temperature contour is convenient but empirical (Meijers et al. 2019). A front is by definition a boundary between water masses of different characteristics. While we chose the range of temperature contours to accord with such definition (Fig. 5), it might not be the case in all regions and seasons. A temperature gradient instead of a temperature contour might be appropriate to highlight sharp water-mass boundaries. In the next section, we propose an alternative ASF proxy based on temperature gradients.

\section{b. Temperature gradients with Sobel edge detection}

We compute the two-dimensional spatial gradient of the temperature field at $300 \mathrm{~m}$ with a Sobel operator [I. Sobel and G. Feldman 1968, unpublished presentation to the Stanford Artificial Intelligence Project (SAIL): "A $3 \times 3$ isotropic gradient operator for image processing"; https://www.researchgate.net/ publication/239398674_An_Isotropic_3x3_Image_Gradient_ Operator]. This heuristic method provides approximate intensity of gradients for each grid point and has been applied on PC maps similar to the PCs of our study to detect oceanic fronts in the Arctic (Hjelmervik and Hjelmervik 2019). It is widely used in image processing to detect edges. Here we apply the Sobel operator on 300-m temperature fields as an objective method highlighting the sharpest horizontal temperature gradients (Fig. 6b). While gradients of less than $0.5^{\circ} \mathrm{C}$ over a $100-\mathrm{km}$ distance appear to be very local and noisy, gradients above $0.5^{\circ} \mathrm{C}(100 \mathrm{~km})^{-1}$ show circumpolar continuity. All gradients above this threshold of $0.5^{\circ} \mathrm{C}(100 \mathrm{~km})^{-1}$ are shown on Fig. $6 \mathrm{~b}$ as a proxy delineating the ASF.

The annual mean picture depicted by this method overall agrees well with the temperature contour methods: continuous and sharp ASF in the Ross Sea and East Antarctic sectors; weaker gradients in the Amundsen and Weddell Sea. However, the initiation of the ASF is located farther east, as a filament is found along the shelf break of the Bellingshausen Sea sector.

Consistent with the temperature contour method, the Sobel method indicates a seasonal sharpening of the ASF in winter, except in the Amundsen Sea where winter gradients decrease (Fig. 7). The seasonal variability of the transition between the Bellingshausen and Ross Sea sectors without and with ASF (respectively) is similar to the temperature contour proxy, with the transition being in the Amundsen Sea in summer and closer to the Ross Sea in winter, leaving weaker gradients in the Bellingshausen and Amundsen sectors in winter (Fig. 7). In winter the Amundsen Sea is invaded with warm waters from farther north (Mallett et al. 2018), which increase the temperature on the continental shelf and therefore decrease the temperature gradient across the shelf break.

The Sobel gradient method allows us to document more complex frontal structure than a simple contour can do. For instance, east of the Weddell Sea embayment as the shelf widens the coastal current divides into branches that follow the coastline and the shelfbreak (Jacobs 1991). These multiple narrow fronts are visible here during the spring and summer months (Fig. 9), which change in winter (approximately from April to August) into a thicker single front along the shelf 


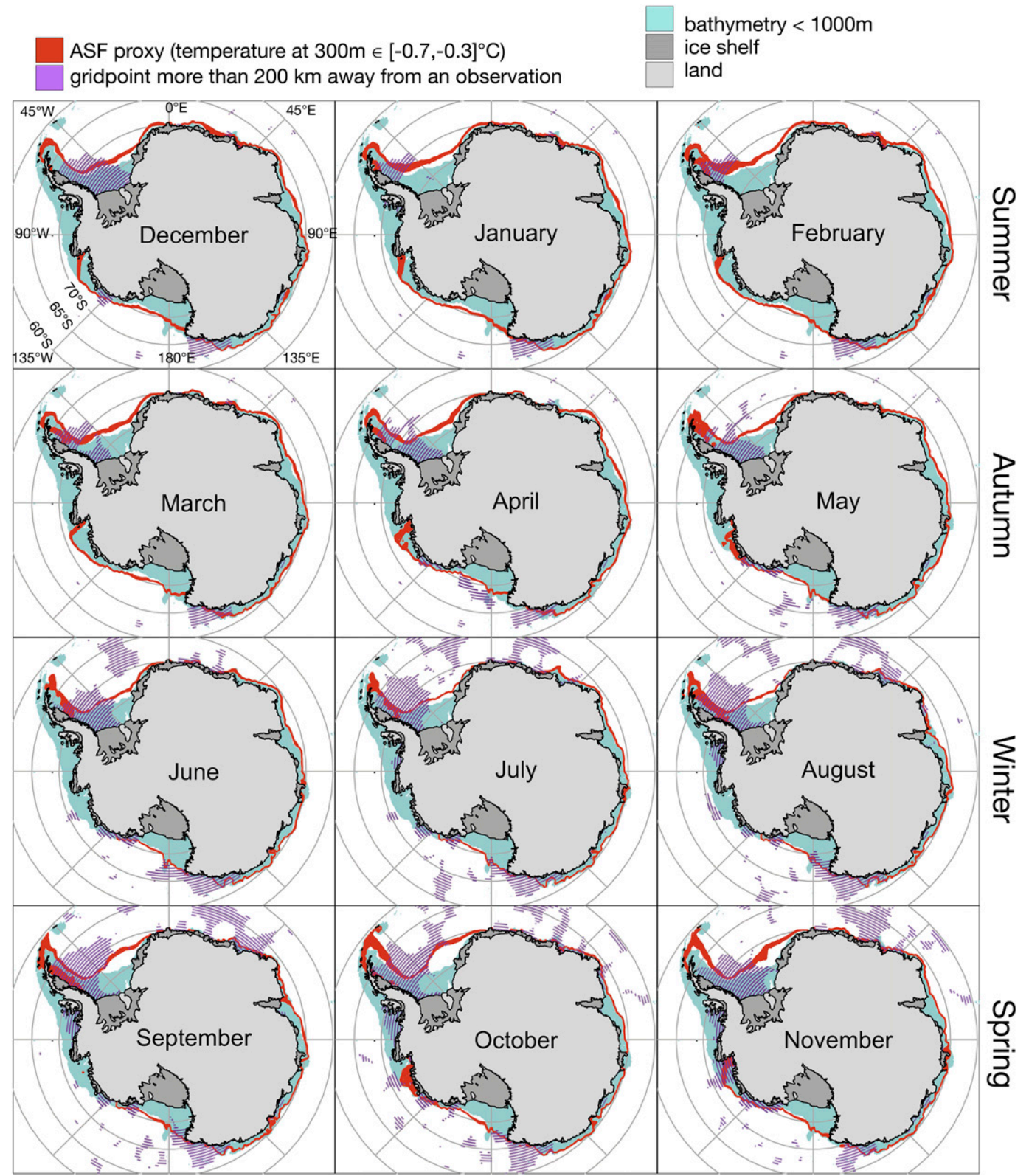

FIG. 7. Representation of the ASF as the temperature at $300 \mathrm{~m}$ that ranges from $-0.7^{\circ}$ to $-0.3^{\circ} \mathrm{C}$ (red). The bathymetry shallower than $1000 \mathrm{~m}$ is in blue. Grid points more than $200 \mathrm{~km}$ away from an observation are in purple.

break. These branches could be a set of shallower open ocean frontal structures that appear in relation to the sea ice melt. They could also be artifacts caused by the seasonal sampling bias. Secondary fronts are also visible along the southern edge of the Ross and Weddell Gyres (Fig. 6b).

\section{Discussion}

\section{a. Antarctic Slope Front position and seasonality}

Both ASF proxies concur on the main climatological and seasonal variability results, providing confidence in our main circumpolar-wide observation-based results. The ASF extends continuously from the Amundsen Sea to the eastern Weddell Sea, closely tracking the continental shelf break, and is associated with sharp temperature gradient. In contrast the West Antarctic Peninsula is not associated with a subsurface temperature front. The exact location in the Amundsen Sea of the transition from the presence of a front to the absence of a front appears seasonally variable (slightly more westward in winter than in summer). A persistent and thinner filament of gradients $>0.5^{\circ} \mathrm{C}(100 \mathrm{~km})^{-1}$ appear offshore the continental shelf of the Bellingshausen Sea (Fig. 9), supported by the recent observation of a front in this region by Thompson et al. (2020). 
The situation in the Weddell Sea sector is a bit more confusing because of the lack of observations in this sector (Fig. S4 of the online supplemental material), but a clear gradient appears to be locked to the shelf break at least in winter, and more generally the frontal structure appears more filamented northward due to secondary fronts associated to the gyre offshore of the shelf break (Jacobs 1991). One potential reason for these filaments could be the interpretation of interannual variability as seasonal signal in data-poor regions. We note, however, that this is unlikely because seasonal variation appears to be much larger than long-term trend, so our interpolation procedure would wash out any subtle long-term trend signal (Hattermann 2018). Last, we speculate that the filamented structure is likely to be an artifact of the sparse data availability or of the shallow extent of our climatology, capturing a set of shallower open-ocean frontal structures in relation to the sea ice melt. This is supported by earlier mooring and full-depth hydrography in this region that found that the ASF preserves a well-defined structure and location year round (Hattermann 2018; Graham et al. 2013; Le Paih et al. 2020; Fahrbach et al. 1992).

The ASF is narrower and sharper in winter as revealed by the consistently tighter contours of temperature (Fig. 8) and the larger values of horizontal gradients (Fig. 9). Two mechanisms might be associated with that seasonal winter sharpening. First, a thermal mechanism in which in winter, the thermocline is steered up by the stronger wind, which brings up the CDW (Thoma et al. 2008; Dutrieux et al. 2014), while the colder atmosphere is cooling down the Shelf Water over the continental shelf, increasing the temperature difference across the front (Zhou et al. 2014; Nøst 2011; Hattermann 2018). Similarly, in summer and in the fresh shelf regime, the downwelling of solar heated surface water along the coast is reducing the temperature difference across the front in summer (Zhou et al. 2014). Second, a dynamical mechanism in which the winter intensification of the ASC, as a barotropic response of the winter wind intensification (e.g., Núñez-Riboni and Fahrbach 2009), strengthen the jets and the associated front, therefore increasing the temperature gradients across the shelf. One must keep in mind that our analysis is limited to $380 \mathrm{~m}$ deep and therefore misses the variability of the ASF that occurs deeper, especially in the fresh shelf regime of East Antarctica.

\section{b. Density gradients across the shelf}

While the temperature field is found to be a very good marker of the ASF (Figs. 3 and 5) as a result of the sharp temperature gradient across the Antarctic shelf break, the temperature field has, in this region of the world, little impact on the density, and therefore the dynamics (Pellichero et al. 2018). It is therefore interesting to investigate the salinity and density gradient across the shelf break, at the position of the ASF as found by the two proxies (see section 3). Consistent with the temperature gradient, the salinity gradient at $300 \mathrm{~m}$ across the ASF is positive circumpolar-wide, excepted in the western peninsula, i.e., in almost all regions, the Antarctic continental shelf is fresher than the offshore ocean (Figs. 10a,b). Interestingly the two property gradients, those of
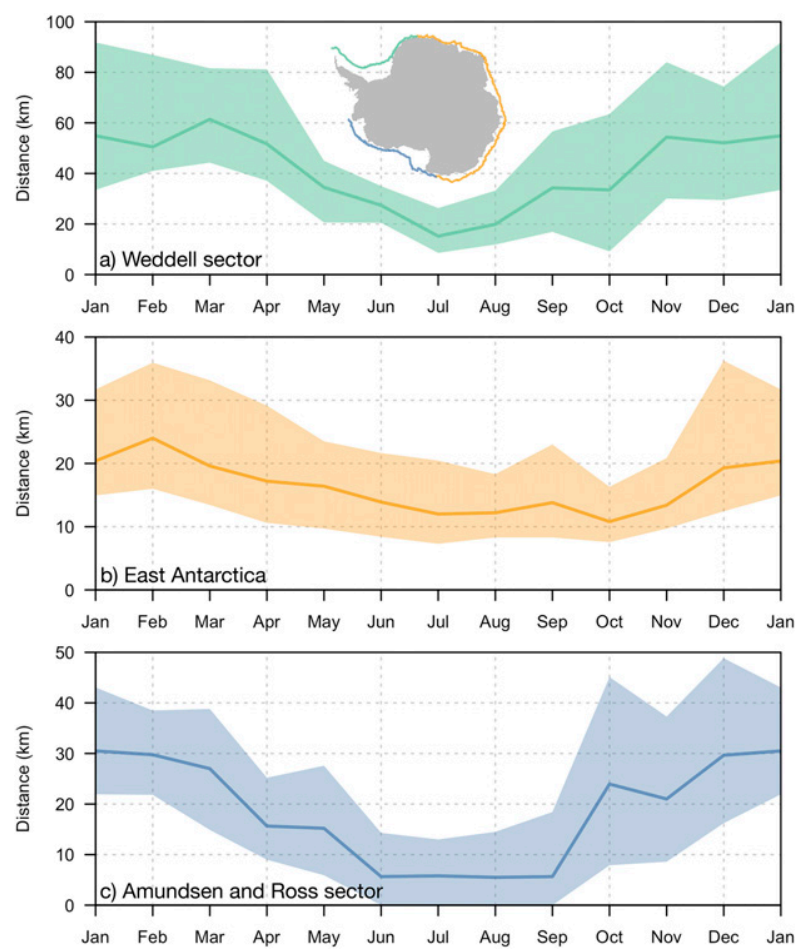

FIG. 8. Seasonal variations in the $300-\mathrm{m}$ horizontal cross-isobath width of the temperature contour range representing the ASF (from $-0.3^{\circ}$ to $-0.7^{\circ} \mathrm{C}$ ) for (a) the Weddell sector, (b) East Antarctica, and (c) the Amundsen and Ross sectors together. The distance is computed along horizontal segments of temperature perpendicular to the $1000-\mathrm{m}$ isobath (see section $3 \mathrm{~b}$ ). The polygons are defined with the $25 \%$ and $75 \%$ quantiles, and the thick line in the middle is the median for each sector. The absence of variations in winter in the Amundsen and Ross sectors in (c) is due to the resolution of $\sim 5^{\circ}$ along the segments. The locations of the sectors are given in the inset in (a).

temperature and salinity, have therefore compensating effect on the density. The resulting potential density gradient is either positive or negative depending on the compensation of salinity with temperature (Fig. 10c), and the level of compensation appears directly associated to the local continental shelf regime (Thompson et al. 2018): fresh continental shelves (Amundsen Sea, eastern Ross and Weddell Seas, and Australian-Antarctic and Enderby Basins) are associated with large northward density gradients dominated by the salinity field; dense continental shelves (western Ross and Weddell Seas, Prydz Bay, and Adélie coast) are associated with weak or negative density gradients because salinity gradients are weak enough so that temperature gradients can compensate; and warm continental shelves (West Peninsula; Bellingshausen Sea) are associated with negative density gradients due to weaker temperature gradients and negative salinity gradients associated to the Polar Front presence farther south in the eastern Pacific basin (Fig. 10).

While the seasonal variability of the ASC is mainly barotropic ( $82 \%$; Núñez-Riboni and Fahrbach 2009), the thermohaline forcing across the shelf break drives a large part of the 


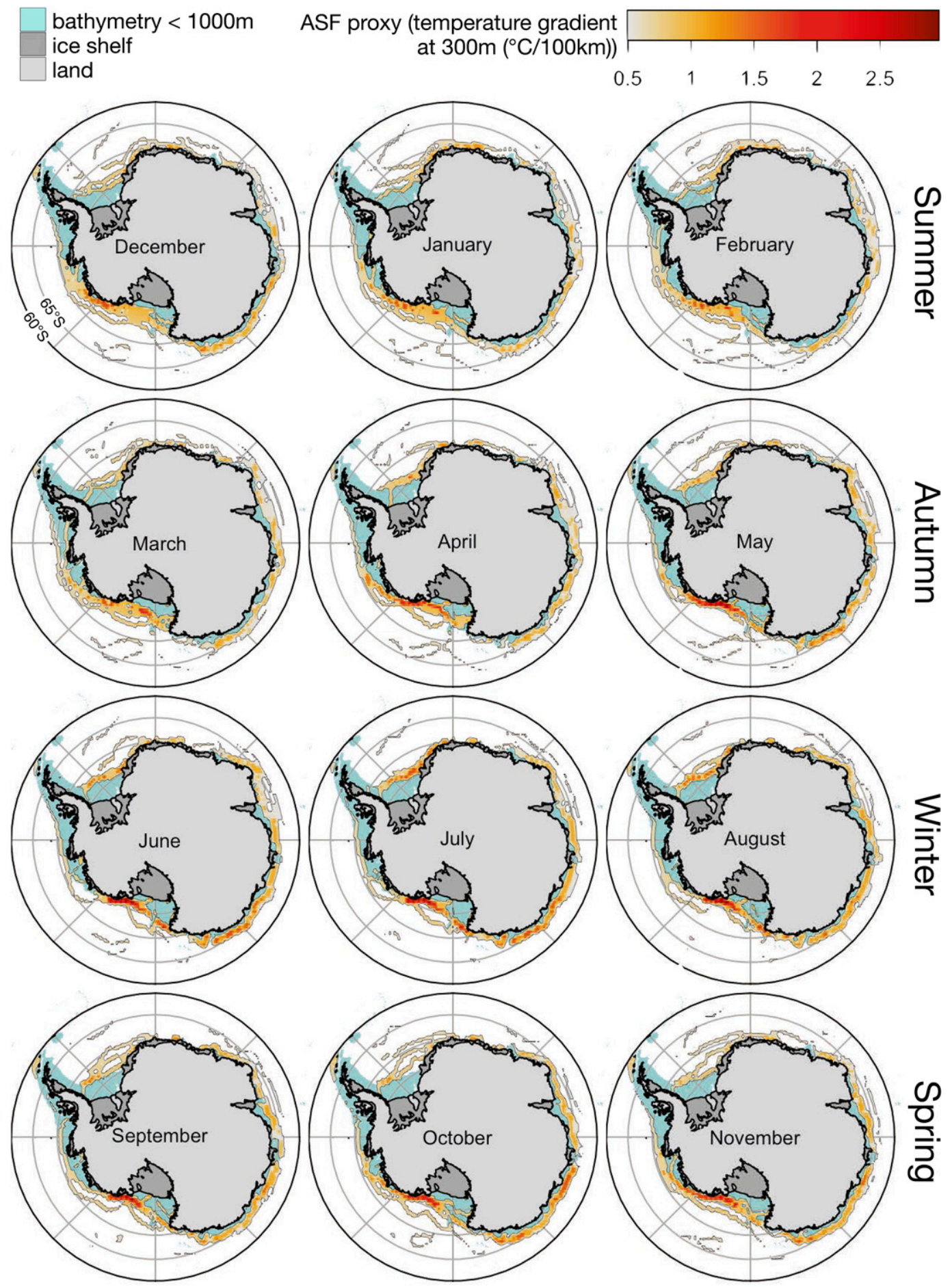

FIG. 9. The ASF is highlighted by the spatial gradient of the temperature field at $300 \mathrm{~m}$ using a Sobel operator. The color bar is truncated at $0.5^{\circ} \mathrm{C}(100 \mathrm{~km})^{-1}$ to visualize the higher gradients.

baroclinic components of the seasonal variability (Hattermann 2018), and it is therefore useful to document the variability of the density field to better understand the seasonal variability of the ASC and ASF. Interestingly, the annual mean horizontal density gradients across the ASF described above stay consistent across all seasons, but the intensity of the gradients overall slightly increase in summer, in contrast with the seasonal variability of the temperature gradient (Fig. 11) and 
a)

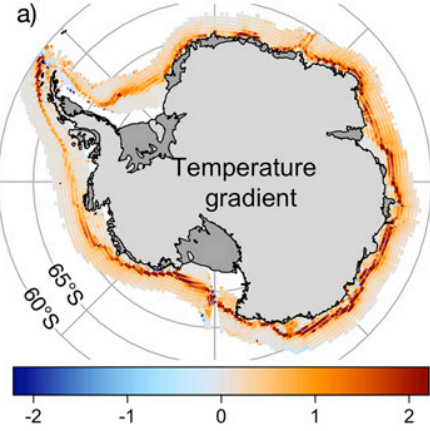

b)

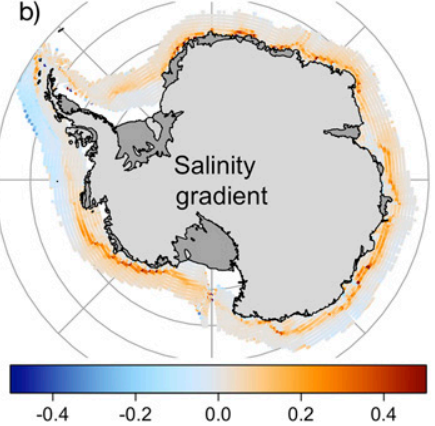

c)

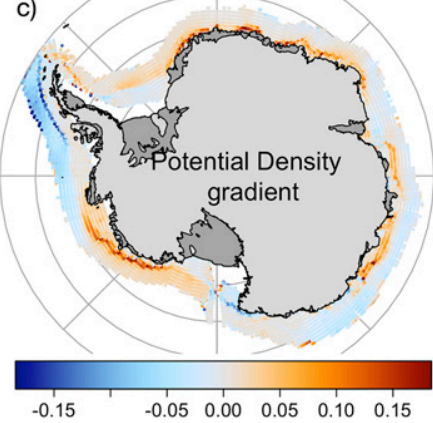

FIG. 10. Annual mean gradients of temperature $\left[{ }^{\circ} \mathrm{C}\left(100 \mathrm{~km}^{-1}\right)\right]$, salinity $\left[\mathrm{psu}\left(100 \mathrm{~km}^{-1}\right)\right]$, and potential density at $300 \mathrm{~m}\left[\mathrm{~kg} \mathrm{~m}^{-3}\left(100 \mathrm{~km}^{-1}\right]\right.$ along segments perpendicular to the $1000-\mathrm{m}$ isobath, representing the shelf break.

in agreement with Zhou et al. (2014). This variability of thermohaline gradients is therefore consistent with a winter slowdown of the baroclinic component of the ASC at the nearsurface, in agreement with the findings of Núñez-Riboni and
Fahrbach (2009), and which would slightly counterbalance the net and stronger barotropic intensification driven in late summer and/or winter (Núñez-Riboni and Fahrbach 2009; Le Paih et al. 2020).

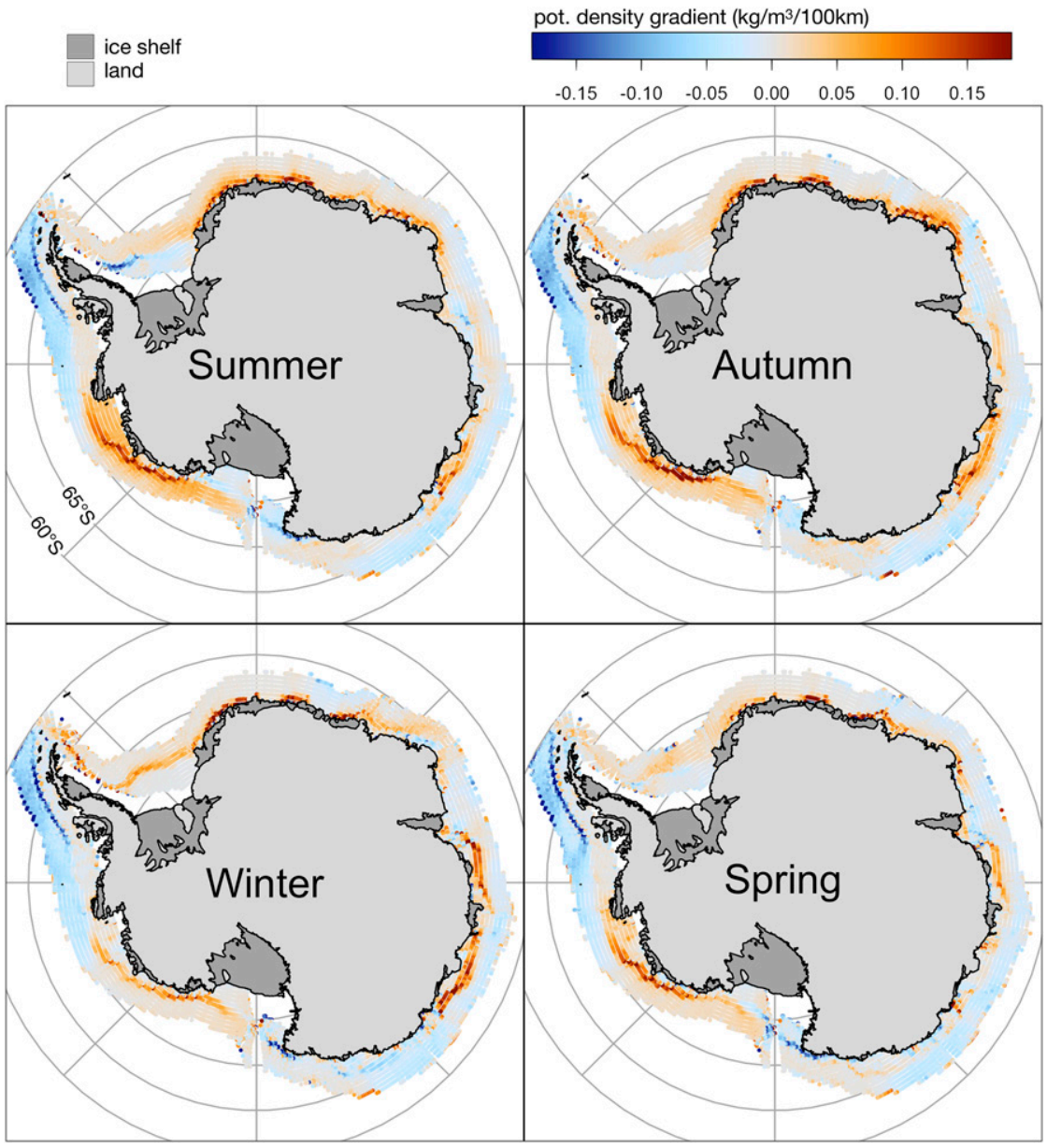

FIG. 11. Gradients of potential density $\left[\mathrm{kg} \mathrm{m}^{-3}(100 \mathrm{~km})^{-1}\right]$ at $300 \mathrm{~m}$ along segments perpendicular to the $1000-\mathrm{m}$ isobath (shelf break), averaged by season: summer (DecemberFebruary), autumn (March-May), winter (June-August), and spring (September-November). The sign convention is that positive gradients from Antarctica to the open ocean are positive on the plot, i.e., pointing northward. 


\section{Conclusions}

Our study aims at describing the mean location and climatological seasonal variability of the ASF from historical in situ hydrographic observations. We use a combination of more than 150000 temperature and salinity profiles acquired south of $60^{\circ} \mathrm{S}$ to derive the main modes of the vertical thermohaline structure of the subpolar Southern Ocean, which we use to construct a seasonal climatology of temperature and salinity in the upper $380 \mathrm{~m}$, including the Antarctic continental shelf regions. Overall, the statistical method used to produce the climatology is based on a functional PCA, which is a way to take into account the covariance of temperature and salinity as well as the continuous nature of the profiles. The optimal interpolation contains front-sharpening and bathymetry-respecting components (Schmidtko et al. 2013). The profiles of our climatology are compared and validated with observations and two other climatologies on a FPCA framework. The mapping of properties at the Antarctic margin is found to be qualitatively improved compared to the two other climatologies. Still, the lack of data in several regions, especially in the ice-covered Weddell Sea, prevents the interpolation from being fully credible in all sectors of the subpolar Southern Ocean (Fig. 7, along with Fig. S2 of the online supplemental material). Despite such local limitation, the novel climatology presented in this study is well designed to fit the main purpose of our study: investigating the annual mean and seasonal climatology of the ASF location, circumpolar-wide, at the Antarctic shelf break.

The statistical decomposition of the vertical structure of the upper ocean is used to investigate the location of the ASF in the $2 \mathrm{D}$ projection formed by the two main modes of variability, in which water mass boundaries clearly stand out. The location of the ASF in this space is then translated into a range of temperature contours for ease of use. The range of temperature from $-0.7^{\circ}$ to $-0.3^{\circ} \mathrm{C}$ at $300 \mathrm{~m}$ is found to produce a plausible tracking of the ASF and is approximately consistent with the boundary established by the PCs. The temperature contour proxy has the great advantage of being an easy proxy to use, but it might be too simplistic and not able to capture the full complexity of the frontal structure (Meijers et al. 2019; Chapman et al.2020). We therefore also propose an alternative proxy to define the ASF, defined as a horizontal temperature gradient threshold at $300 \mathrm{~m}$. We draw on a method that is widely used in image processing to objectively detect the main temperature gradient from our climatological field (Sobel gradients). The method detects large water-mass gradients located at the shelf break, associated with the ASF.

While a number of local analyses of the ASF have been developed over the years [see the review by Thompson et al. (2018)], an updated representation of its circumpolar-wide climatological extent and seasonal variability rooted in the recently grown in situ observation network. Here, we provide a fit-for-purpose seasonal climatology of the subpolar Southern Ocean and propose two ASF proxies to fill this gap. Beyond representing an important benchmark for the evaluation of the ocean and climate models in this critical part of the world, our results are timely and complementary to the validation and usage of the currently growing development of satellite altimetrybased products of sea surface height in the sea ice sectors, which will undoubtedly bring an important new sight on ASF dynamics in the coming years (Armitage et al. 2018; Dotto et al. 2018; Naveira Garabato et al. 2019).

Acknowledgments. We thank Tore Hattermann and an anonymous reviewer for their pertinent comments that greatly improved the quality of the paper. Author Pauthenet received funding from the European Research Council (ERC) under the European Union's Horizon 2020 research and innovation program (Grant Agreement 637770).

Data availability statement. The monthly climatology of the upper Southern Ocean south of $60^{\circ} \mathrm{S}$ computed in this study is available here https://doi.org/10.5281/zenodo.4071906. The code for computing FPCA of hydrographic profiles is available at https://doi.org/10.5281/zenodo.4073123. The code for the optimal interpolation is available at https:/github.com/ EPauthenet/Optimal_interpolation. The NOAA World Ocean Database is available at https:/www.nodc.noaa.gov/OC5/ SELECT/dbsearch/dbsearch.html. The PANGEA database is available at https://www.pangaea.de/. The Argo data were collected and made freely available by the International Argo Program and the national programs that contribute to it (https:// argo.ucsd.edu; https://www.ocean-ops.org). The Argo Program is part of the Global Ocean Observing System. The marinemammal data were collected and made freely available by the International MEOP Consortium and the national programs that contribute to it (http://www.meop.net). The Monthly Isopycnal and Mixed-layer Ocean Climatology (MIMOC) is available at https:/www.pmel.noaa.gov/mimoc/. The World Ocean Atlas (WOA18) is available at https:/www.nodc.noaa.gov/ OC5/woa18/woa18data.html.

\section{REFERENCES}

Abrahamsen, E. P., and Coauthors, 2019: Stabilization of dense Antarctic water supply to the Atlantic Ocean overturning circulation. Nat. Climate Change, 9, 742-746, https://doi.org/ 10.1038/s41558-019-0561-2.

Argo, 2020: Argo float data and metadata from Global Data Assembly Centre (Argo GDAC). SEANOE, accessed 13 April 2021, https://doi.org/10.17882/42182.

Armitage, T. W., R. Kwok, A. F. Thompson, and G. Cunningham, 2018: Dynamic topography and sea level anomalies of the southern ocean: Variability and teleconnections. J. Geophys. Res. Oceans, 123, 613-630, https://doi.org/10.1002/ 2017JC013534.

Auger, M., R. Morrow, E. Kestenare, J.-B. Sallée, and R. Cowley, 2021: Southern Ocean in-situ temperature trends over 25 years emerge from interannual variability. Nat. Commun., 12, 514, https://doi.org/10.1038/s41467-020-20781-1.

Bamber, J. L., M. Oppenheimer, R. E. Kopp, W. P. Aspinall, and R. M. Cooke, 2019: Ice sheet contributions to future sea-level rise from structured expert judgment. Proc. Natl. Acad. Sci. USA, 116, 11 195-11 200, https://doi.org/10.1073/pnas.1817205116.

Barnes, S. L., 1964: A technique for maximizing details in numerical weather map analysis. J. Appl. Meteor., 3, 396-409, https:// doi.org/10.1175/1520-0450(1964)003<0396:ATFMDI> 2.0.CO;2. 
Bronselaer, B., M. Winton, S. M. Griffies, W. J. Hurlin, K. B. Rodgers, O. V. Sergienko, R. J. Stouffer, and J. L. Russell, 2018: Change in future climate due to Antarctic meltwater. Nature, 564, 53-58, https://doi.org/10.1038/s41586-0180712-z.

Chapman, C., M.-A. Lea, A. Meyer, J. Sallée, and M. Hindell, 2020: Defining Southern Ocean fronts and their influence on biological and physical processes in a changing climate. Nat. Climate Change, 10, 209-219, https://doi.org/10.1038/s41558020-0705-4.

Chavanne, C. P., K. J. Heywood, K. W. Nicholls, and I. Fer, 2010: Observations of the Antarctic Slope Undercurrent in the southeastern Weddell Sea. Geophys. Res. Lett., 37, L13601, https://doi.org/10.1029/2010GL043603.

Daae, K., T. Hattermann, E. Darelius, and I. Fer, 2017: On the effect of topography and wind on warm water inflow-An idealized study of the Southern Weddell Sea continental shelf system. J. Geophys. Res. Oceans, 122, 2622-2641, https://doi.org/ 10.1002/2016JC012541.

Dotto, T. S., and Coauthors, 2018: Variability of the Ross Gyre, Southern Ocean: Drivers and responses revealed by satellite altimetry. Geophys. Res. Lett., 45, 6195-6204, https://doi.org/ 10.1029/2018GL078607.

Dutrieux, P., and Coauthors, 2014: Strong sensitivity of pine island ice-shelf melting to climatic variability. Science, $\mathbf{3 4 3}, 174-178$, https://doi.org/10.1126/science.1244341.

Fahrbach, E., G. Rohardt, and G. Krause, 1992: The Antarctic coastal current in the southeastern Weddell Sea. Polar Bio., 12, 171-182, https://doi.org/10.1007/BF00238257.

Flexas, M. M., M. P. Schodlok, L. Padman, D. Menemenlis, and A. H. Orsi, 2015: Role of tides on the formation of the Antarctic Slope Front at the Weddell-Scotia Confluence. J. Geophys. Res. Oceans, 120, 3658-3680, https://doi.org/10.1002/2014JC010372.

Golledge, N. R., E. D. Keller, N. Gomez, K. A. Naughten, J. Bernales, L. D. Trusel, and T. L. Edwards, 2019: Global environmental consequences of twenty-first-century ice-sheet melt. Nature, 566, 65-72, https://doi.org/10.1038/s41586-0190889-9.

Graham, J. A., K. J. Heywood, C. P. Chavanne, and P. R. Holland, 2013: Seasonal variability of water masses and transport on the Antarctic continental shelf and slope in the southeastern Weddell Sea. J. Geophys. Res. Oceans, 118, 2201-2214, https:// doi.org/10.1002/jgrc.20174.

Hattermann, T., 2018: Antarctic thermocline dynamics along a narrow shelf with easterly winds. J. Phys. Oceanogr., 48, 24192443, https://doi.org/10.1175/JPO-D-18-0064.1.

—, L. H. Smedsrud, O. A. Nøst, J. M. Lilly, and B. K. GaltonFenzi, 2014: Eddy-resolving simulations of the Fimbul Ice Shelf cavity circulation: Basal melting and exchange with open ocean. Ocean Modell., 82, 28-44, https://doi.org/10.1016/ j.ocemod.2014.07.004.

Heywood, K. J., R. A. Locarnini, R. D. Frew, P. F. Dennis, and B. A. King, 1998: Transport and water masses of the Antarctic slope front system in the eastern Weddell Sea. Ocean, Ice, and Atmosphere: Interactions at the Antarctic Continental Margin. S. S. Jacobs and R. F. Weiss, Eds., Antarctic Research Series, Vol. 75, Amer. Geophys. Union, 203-214.

Hjelmervik, K. B., and K. T. Hjelmervik, 2019: Detection of oceanographic fronts on variable water depths using empirical orthogonal functions. IEEE J. Oceanic Eng., 45, 915-926, https://doi.org/10.1109/JOE.2019.2917456.

Holland, P. R., T. J. Bracegirdle, P. Dutrieux, A. Jenkins, and E. J. Steig, 2019: West Antarctic ice loss influenced by internal climate variability and anthropogenic forcing. Nat. Geosci., 12, 718-724, https://doi.org/10.1038/s41561-019-0420-9.

Hyndman, R. J., 1996: Computing and graphing highest density regions. Amer. Stat., 50, 120-126.

Jacobs, S. S., 1991: On the nature and significance of the Antarctic Slope Front. Mar. Chem., 35, 9-24, https://doi.org/10.1016/ S0304-4203(09)90005-6.

Jenkins, A., P. Dutrieux, S. Jacobs, E. J. Steig, G. H. Gudmundsson, J. Smith, and K. J. Heywood, 2016: Decadal ocean forcing and Antarctic ice sheet response: Lessons from the Amundsen Sea. Oceanography, 29, 106-117, https://doi.org/10.5670/ oceanog.2016.103.

- D. Shoosmith, P. Dutrieux, S. Jacobs, T. W. Kim, S. H. Lee, H. K. Ha, and S. Stammerjohn, 2018: West Antarctic ice sheet retreat in the Amundsen Sea driven by decadal oceanic variability. Nat. Geosci., 11, 733-738, https://doi.org/10.1038/s41561018-0207-4.

Jones, D. C., H. J. Holt, A. J. Meijers, and E. Shuckburgh, 2019: Unsupervised clustering of Southern Ocean Argo float temperature profiles. J. Geophys. Res. Oceans, 124, 390-402, https://doi.org/10.1029/2018JC014629.

Jourdain, N. C., X. Asay-Davis, T. Hattermann, F. Straneo, H. Seroussi, C. M. Little, and S. Nowicki, 2020: A protocol for calculating basal melt rates in the ISMIP6 Antarctic ice sheet projections. Cryosphere, 14, 3111-3134, https://doi.org/10.5194/ tc-14-3111-2020.

Khazendar, A., and Coauthors, 2016: Rapid submarine ice melting in the grounding zones of ice shelves in west Antarctica. Nat. Commun., 7, 13243, https://doi.org/10.1038/ncomms13243.

Kim, Y. S., and A. H. Orsi, 2014: On the variability of Antarctic circumpolar current fronts inferred from 1992-2011 altimetry. J. Phys. Oceanogr., 44, 3054-3071, https://doi.org/10.1175/ JPO-D-13-0217.1.

Kuragano, T., and M. Kamachi, 2000: Global statistical space-time scales of oceanic variability estimated from the TOPEX/Poseidon altimeter data. J. Geophys. Res., 105, 955-974, https://doi.org/ 10.1029/1999JC900247.

Kuusela, M., and M. L. Stein, 2018: Locally stationary spatiotemporal interpolation of Argo profiling float data. Proc. Roy. Soc., 474A, 20180400, https://doi.org/10.1098/RSPA.2018.0400.

Lago, V., and M. H. England, 2019: Projected slowdown of Antarctic bottom water formation in response to amplified meltwater contributions. J. Climate, 32, 6319-6335, https:// doi.org/10.1175/JCLI-D-18-0622.1.

Le Paih, N., T. Hattermann, O. Boebel, T. Kanzow, C. Lüpkes, G. Rohardt, V. Strass, and S. Herbette, 2020: Coherent seasonal acceleration of the Weddell sea boundary current system driven by upstream winds. J. Geophys. Res. Oceans, 125, e2020JC016316, https://doi.org/10.1029/2020JC016316.

Locarnini, R. A., and Coauthors, 2018: Temperature. Vol. 1, World Ocean Atlas 2018, NOAA Atlas NESDIS 81, 52 pp., https:// www.ncei.noaa.gov/sites/default/files/2021-03/woa18_vol1.pdf.

Mallett, H. K. W., L. Boehme, M. Fedak, K. J. Heywood, D. P. Stevens, and F. Roquet, 2018: Variation in the distribution and properties of circumpolar deep water in the eastern Amundsen Sea, on seasonal timescales, using seal-borne tags. Geophys. Res. Lett., 45, 4982-4990, https://doi.org/10.1029/ 2018 GL077430.

Maze, G., H. Mercier, R. Fablet, P. Tandeo, M. L. Radcenco, P. Lenca, C. Feucher, and C. Le Goff, 2017: Coherent heat patterns revealed by unsupervised classification of Argo temperature profiles in the North Atlantic Ocean. Prog. Oceanogr., 151, 275-292, https://doi.org/10.1016/j.pocean.2016.12.008. 
Meijers, A. J. S., M. P. Meredith, E. J. Murphy, D. P. Chambers, M. Belchier, and E. F. Young, 2019: The role of ocean dynamics in king penguin range estimation. Nat. Climate Change, 9, 120-121, https://doi.org/10.1038/s41558-018-0388-2.

Moorman, R., A. K. Morrison, and A. M. Hogg, 2020: Thermal responses to Antarctic ice shelf melt in an eddy rich global ocean-sea-ice model. J. Climate, 33, 6599-6620, https://doi.org/ 10.1175/JCLI-D-19-0846.1.

Naveira Garabato, A. C., and Coauthors, 2019: Phased response of the subpolar Southern Ocean to changes in circumpolar winds. Geophys. Res. Lett., 46, 6024-6033, https://doi.org/10.1029/ 2019GL082850.

Nøst, O. A., 2011: Eddy overturning of the Antarctic slope front controls glacial melting in the eastern Weddell Sea. J. Geophys. Res., 116, C11014, https://doi.org/10.1029/2011JC006965.

Núñez-Riboni, I., and E. Fahrbach, 2009: Seasonal variability of the Antarctic Coastal Current and its driving mechanisms in the Weddell Sea. Deep-Sea Res. I, 56, 1927-1941, https:// doi.org/10.1016/j.dsr.2009.06.005.

Ohshima, K. I., T. Takizawa, S. Ushio, and T. Kawamura, 1996: Seasonal variations of the Antarctic coastal ocean in the vicinity of Lützow-Holm Bay. J. Geophys. Res., 101, 20 617-20 628, https://doi.org/10.1029/96JC01752.

Orsi, A. H., G. C. Johnson, and J. L. Bullister, 1999: Circulation, mixing, and production of Antarctic bottom water. Prog. Oceanogr., 43, 55-109, https://doi.org/10.1016/S0079-6611(99) 00004-X.

Pauthenet, E., F. Roquet, G. Madec, and D. Nerini, 2017: A linear decomposition of the Southern Ocean thermohaline structure. J. Phys. Oceanogr., 47, 29-47, https://doi.org/10.1175/JPO-D16-0083.1.

,,--- , C. Guinet, M. Hindell, C. R. McMahon, R. Harcourt, and D. Nerini, 2018: Seasonal meandering of the polar front upstream of the Kerguelen Plateau. Geophys. Res. Lett., 45, 9767-9774, https://doi.org/10.1029/2018GL079614.

,,$-- \ldots$, J.-B. Sallée, and D. Nerini, 2019: The thermohaline modes of the global ocean. J. Phys. Oceanogr., 49, 25352552, https://doi.org/10.1175/JPO-D-19-0120.1.

Pellichero, V., J. Sallée, S. Schmidtko, F. Roquet, and J. Charrassin, 2017: The ocean mixed layer under Southern Ocean sea-ice: Seasonal cycle and forcing. J. Geophys. Res. Oceans, 122, 16081633, https://doi.org/10.1002/2016JC011970.

$\longrightarrow,-$ C. Chapman, and S. M. Downes, 2018: The Southern Ocean meridional overturning in the sea-ice sector is driven by freshwater fluxes. Nat. Commun., 9, 1789, https://doi.org/ 10.1038/s41467-018-04101-2.

Previdi, M., and L. M. Polvani, 2016: Anthropogenic impact on Antarctic surface mass balance, currently masked by natural variability, to emerge by mid-century. Environ. Res. Lett., 11, 094001, https://doi.org/10.1088/1748-9326/11/9/094001.

Pritchard, H., S. Ligtenberg, H. Fricker, D. Vaughan, M. Van den Broeke, and L. Padman, 2012: Antarctic ice-sheet loss driven by basal melting of ice shelves. Nature, 484, 502-505, https:// doi.org/10.1038/nature10968.

Purkey, S. G., and G. C. Johnson, 2010: Warming of global abyssal and deep Southern Ocean waters between the 1990s and 2000s: Contributions to global heat and sea level rise budgets. J. Climate, 23, 6336-6351, https://doi.org/10.1175/2010JCLI3682.1.

_, and _ 2012: Global contraction of Antarctic bottom water between the 1980s and 2000s. J. Climate, 25, 5830-5844, https:// doi.org/10.1175/JCLI-D-11-00612.1.

—_, and —, 2013: Antarctic bottom water warming and freshening: Contributions to sea level rise, ocean freshwater budgets, and global heat gain. J. Climate, 26, 6105-6122, https://doi.org/10.1175/JCLI-D-12-00834.1.

Ramsay, J. O., and B. Silverman, 2005: Functional Data Analysis. Springer, $426 \mathrm{pp}$.

- S. Graves, and G. Hooker, 2020: fda: Functional Data Analysis. R package, version 5.1.4, https:/CRAN.R-project.org/ package $=$ fda.

R Core Team, 2017: R: A Language and Environment for Statistical Computing. R Foundation for Statistical Computing, https://www.R-project.org/.

Rignot, E., J. Mouginot, B. Scheuchl, M. van den Broeke, M. J. van Wessem, and M. Morlighem, 2019: Four decades of Antarctic ice sheet mass balance from 1979-2017. Proc. Natl. Acad. Sci. USA, 116, 1095-1103, https://doi.org/10.1073/ pnas. 1812883116.

Roquet, F., and Coauthors, 2014: A southern Indian Ocean database of hydrographic profiles obtained with instrumented elephant seals. Sci. Data, 1, 140028, https://doi.org/10.1038/ sdata.2014.28.

Rosso, I., M. Mazloff, L. Talley, S. Purkey, N. Freeman, and G. Maze, 2020: Water mass and biogeochemical variability in the Kerguelen sector of the Southern Ocean: A machine learning approach for a mixing hot spot. J. Geophys. Res. Oceans, 125, e2019JC015877, https://doi.org/10.1029/2019JC015877.

Ryan, S., H. H. Hellmer, M. Janout, E. Darelius, L. Vignes, and M. Schröder, 2020: Exceptionally warm and prolonged flow of warm deep water toward the Filchner-Ronne ice shelf in 2017. Geophys. Res. Lett., 47, e2020GL088119, https://doi.org/10.1029/ 2020GL088119.

Sadai, S., A. Condron, R. DeConto, and D. Pollard, 2020: Future climate response to Antarctic ice sheet melt caused by anthropogenic warming. Sci. $A d v .$, 6, eaaz1169, https://doi.org/ 10.1126/sciadv.aaz1169.

Schmidtko, S., G. C. Johnson, and J. M. Lyman, 2013: MIMOC: A global monthly isopycnal upper-ocean climatology with mixed layers. J. Geophys. Res. Oceans, 118, 1658-1672, https:// doi.org/10.1002/jgrc.20122.

—, K. J. Heywood, A. F. Thompson, and S. Aoki, 2014: Multidecadal warming of Antarctic waters. Science, 346, 12271231, https://doi.org/10.1126/science.1256117.

_- L. Stramma, and M. Visbeck, 2017: Decline in global oceanic oxygen content during the past five decades. Nature, 542, 335339, https://doi.org/10.1038/nature21399.

Seroussi, H., and Coauthors, 2020: ISMIP6 Antarctica: A multimodel ensemble of the Antarctic ice sheet evolution over the 21st century. Cryosphere, 14, 3033-3070, https://doi.org/ 10.5194/tc-14-3033-2020.

Silvano, A., and Coauthors, 2020: Recent recovery of Antarctic bottom water formation in the Ross Sea driven by climate anomalies. Nat. Geosci., 13, 780-786, https://doi.org/10.1038/ S41561-020-00655-3.

Smith, B., and Coauthors, 2020: Pervasive ice sheet mass loss reflects competing ocean and atmosphere processes. Science, 368, 1239-1242, https://doi.org/10.1126/science.aaz5845.

Snow, K., A. M. Hogg, B. M. Sloyan, and S. M. Downes, 2016: Sensitivity of Antarctic bottom water to changes in surface buoyancy fluxes. J. Climate, 29, 313-330, https://doi.org/ 10.1175/JCLI-D-15-0467.1.

Spence, P., S. M. Griffies, M. H. England, A. M. Hogg, O. A. Saenko, and N. C. Jourdain, 2014: Rapid subsurface warming and circulation changes of Antarctic coastal waters by poleward shifting winds. Geophys. Res. Lett., 41, 4601-4610, https://doi.org/10.1002/2014GL060613. 
Stewart, A. L., A. Klocker, and D. Menemenlis, 2019: Acceleration and overturning of the Antarctic Slope Current by winds, eddies, and tides. J. Phys. Oceanogr., 49, 2043-2074, https:// doi.org/10.1175/JPO-D-18-0221.1.

Sugiyama, J., and K. Kobayashi, 2016: wvtool: Image tools for automated wood identification. R package version 1.0, https:// CRAN.R-project.org $/$ package $=$ wvtool .

Sun, Q., C. M. Little, A. M. Barthel, and L. Padman, 2020: A clustering-based approach to ocean model-data comparison around Antarctica. Ocean Sci., 17, 131-145, https://doi.org/ 10.5194/OS-17-131-2021.

Sverdrup, H. U., 1954: The currents off the coast of Queen Maud Land. Norsk Geografisk Tidsskrift, 14, 239-249, https://doi.org/ 10.1080/00291955308542731.

Thoma, M., A. Jenkins, D. Holland, and S. Jacobs, 2008: Modelling circumpolar deep water intrusions on the Amundsen Sea continental shelf, Antarctica. Geophys. Res. Lett., 35, L18602, https://doi.org/10.1029/2008GL034939.

Thompson, A. F., K. J. Heywood, S. Schmidtko, and A. L. Stewart, 2014: Eddy transport as a key component of the Antarctic overturning circulation. Nat. Geosci., 7, 879-884, https:// doi.org/10.1038/ngeo2289.

- A. L. Stewart, P. Spence, and K. J. Heywood, 2018: The Antarctic Slope Current in a changing climate. Rev. Geophys., 56, 741-770, https://doi.org/10.1029/2018RG000624.
— K. G. Speer, and L. M. Schulze Chretien, 2020: Genesis of the Antarctic Slope Current in West Antarctica. Geophys. Res. Lett., 47, e2020GL087802, https://doi.org/10.1029/2020GL087802.

Treasure, A. M., and Coauthors, 2017: Marine mammals exploring the oceans pole to pole. Oceanography, 30, 132-138, https:// doi.org/10.5670/oceanog.2017.234.

Vernet, M., and Coauthors, 2019: The Weddell Gyre, Southern Ocean: Present knowledge and future challenges. Rev. Geophys., 57, 623-708, https://doi.org/10.1029/2018RG000604.

Williams, G. D., N. L. Bindoff, S. J. Marsland, and S. R. Rintoul, 2008: Formation and export of dense shelf water from the Adélie Depression, East Antarctica. J. Geophys. Res. Oceans, 113, C04039, https://doi.org/10.1029/2007JC004346.

Wouters, B., J. L. Bamber, M. R. van den Broeke, J. T. M. Lenaerts, and I. Sasgen, 2013: Limits in detecting acceleration of ice sheet mass loss due to climate variability. Nat. Geosci., 6 , 613-616, https://doi.org/10.1038/ngeo1874.

Zhou, Q., T. Hattermann, O. Nøst, M. Biuw, K. Kovacs, and C. Lydersen, 2014: Wind-driven spreading of fresh surface water beneath ice shelves in the eastern Weddell Sea. J. Geophys. Res. Oceans, 119, 3818-3833, https://doi.org/ 10.1002/2013JC009556.

Zweng, M. M., and Coauthors, 2018: Salinity. Vol. 2, World Ocean Atlas 2018, NOAA Atlas NESDIS 82, 50 pp., https:// www.ncei.noaa.gov/sites/default/files/2020-04/woa18_vol2.pdf . 